\title{
LA PROGRESIVA HUMANIZACIÓN DE LOS PROCESOS DE INSOLVENCIA DE PERSONAS NATURALES: DESDE LA SERVIDUMBRE E INFAMIA HASTA LOS PROCESOS CONCURSALES DE CONSUMIDORES
}

[The Progressive Humanization of Insolvency Procedures Involving Natural Persons: From Debt Bondage and Infamy to Consumer's Insolvency Procedures]

\author{
Álvaro Pérez-Ragone* \\ Pontificia Universidad Católica de Valparaíso, Chile
}

\begin{abstract}
RESUMEN
El tratamiento de la insolvencia ha sufrido un proceso histórico de varios siglos. La deuda restante moderna y el fracaso comercial o industrial se corresponde con el desarrollo de la ley de bancarrota
\end{abstract}

Abstract

The treatment of insolvency has undergone a historical process for several centuries. The modern outstanding debt and the commercial or industrial failure are consistent with the development of

RECiBIDo el 23 de octubre y ACEPTADo el 13 de diciembre de 2013

* Profesor de Derecho procesal civil de la Pontificia Universidad Católica de Valparaíso. Este aporte fue posible gracias a los diálogos mantenidos con el colega Prof. Dr. Christian Baldus y la Dra. Schmon en la Universidad de Heidelberg en el invierno 2012/2013 quienes, dentro del marco de un programa de la DAAD acompañaron mi estadía como profesor visitante a cargo de un seminario durante tres meses. Todo lo valioso en aporte interdisciplinario es mérito de ellos. También se dio dentro del cierre del proyecto FONDECYT No 1111021: "Principios de la tutela ejecutiva del crédito" ya concluido. El texto fue originalmente escrito en alemán y esta es la versión traducida al español cuya adecuación a reglas de edición y correcciones se las agradezco a los ayudantes del Departamento de Derecho Procesal Civil de la PUCV, Gabriela Palacios y Sebastián Vergara de la Rivera. Finalmente durante la estadía el tedioso escaneo y orden de las fuentes fue realizado por el ayudante Juan Magasich. 
privada de las personas. La historia del equipo de desarrollo de la realización de los resultados de la hoja de ejecución en una prisión de los deudores del siglo XXI. Ahora, el trabajo da al deudor una segunda oportunidad de comparar la deuda y ya ha jugado un papel importante en Roma y en algunas culturas medievales (servidumbre por deudas) y modernos.

Palabras clave

Servidumbre por deudas - Insolvencia-Consumidores. private individual insolvency act. The history of the team that developed the implementation of the results of the worksheet in a prison for the $21^{\text {st }}$ century debtors. Now, work gives the debtor a second chance for comparing the debt and has played an important role in Rome and some medieval and modern cultures (debt bondage).

KEYWORDS

Debt bondage- Insolvency - Consumers.

\section{INTRODUCCIÓN}

El Código [Ordenanza] Concursal alemán (Konkursordnung) alemán rigió desde el 1 de octubre de 1879 hasta el 31 de diciembre de 1999; luego fue reemplazado y rige hasta hoy como Código [Ordenanza] de Insolvencia (Insolvenzordnung). El verbo concurrere, por un lado, significa "encuentro de unos, competencia o concurrencia”, y ellos se relacionan con la carrera o competencia, en la que se encuentran los acreedores en relación a su deudor común a los efectos de poder satisfacer su crédito. Por otro lado, el término "insolvencia" deriva del verbo latino solvere, que quiere decir "pagar", y por ello es que resulta consecuente, a primera vista, su relación con un procedimiento pensado justamente cuando el deudor está imposibilitado o incapacitado de pagar.

Las diferentes designaciones dadas al proceso de insolvencia no deben conducir a confusiones. Justamente antes del Código Código de Insolvencia hubo al menos dos procedimientos que regulaban el fenómeno concursal: por un lado, el procedimiento de liquidación universal; y por el otro el de convenio o transacción, aunque en ambos se hablaba del elemento común de la insolvencia ${ }^{1}$. En relación a la incapacidad de pago y sobreendeudamiento como causales para la apertura de un proceso de insolvencia, son conceptos cuya delimitación en comprensión y extensión nos son claros hasta hoy ${ }^{2}$.

${ }^{1}$ KoHLER, Joseph, Lehrbuch des Konkursrechts (Stuttgart, 1891), pp. 1-4; cfr. BAYER, Hieronymus, Theorie des Concurs-Processes nach gemeinem Rechte ( $4^{\mathrm{a}}$ edición y $2^{\mathrm{a}}$ impresión, München, 1868), IV, pp. 3 -8.

${ }^{2}$ SCHÄFER, Thiemo, Der Eröffnunggrund der Überschuldung (Baden-Baden, Diss. Köln, 2012), pp. 261-271. 
En todo caso, se trata del fenómeno de la crisis del deudor en tanto que, ora por incapacidad de pago o iliquidez actual, ora por sobreendeudamiento, se encuentra en estado (actual o inminente) de insolvencia, es decir, no dispone de suficiente patrimonio, para el cumplimiento o cobertura de sus obligaciones exigibles ${ }^{3}$.

La ejecución universal se contrapone así a la singular, siendo ésta menos compleja en los intereses en juego (aún con pluralidad de acreedores) en contra de un deudor común, pero solvente. El concurso de acreedores frente a un mismo deudor insolvente requiere, por un lado, el equilibrio entre los intereses jurídicos y económicos de aquellos a ser satisfechos parcialmente y los del afectado por su insuficiencia patrimonial. Dejó implísito que también interesa a la dinámica económico-social del Estado una adecuada regulación, lo que por cierto se evidenciará en el tratamiento histórico que se desarrolla infra 4 .

Entonces, ¿cómo se reparte el riesgo de la incapacidad de pago de un deudor común? En general existen las siguientes posibilidades polarizadas para canalizar procesalmente la insolvencia: $i$ ) una bajo la fuerte dirección de los acreedores con una reducida intervención del tribunal; ii) la otra, sujeta a la dirección principal por parte del tribunal del proceso, con la posibilidad tanto para acreedores como para el deudor del impulso y control del proceso 5 . Ambas alternativas necesitan necesitan contemplar (intensificando todas por igual o algunas más acentuadas que otras) los siguientes aspectos: $i$ ) obtener una correcta información del patrimonio del deudor, $i i)$ evitar fraudes y actos de colusión entre los acreedores y/o de alguno de estos con el deudor, iii) finalmente la posibilidad -tanto para las personas naturales como para las empresas- ya sea de liquidar su patrimonio, o bien, de acudir a una alternativa de saneamiento, reorganización o liberación de deudas ${ }^{6}$. Siendo que la

${ }^{3}$ Podría partirse de una noción más amplia a la de insolvencia con el término sobreendeudamiento (que en este artículo se entiende aplicable tanto al sujeto pasivo empresario como a la persona natural consumidor). Noción amplia que permitirá incluir diversos niveles o grados de crisis, los que por cierto no tenían contemplación o relevancia legal, sí fáctica para facilitar un tratamiento más o menos riguroso y limitativo de los derechos del deudor. En el caso de la Ley italiana de enero del 2012, en su art' piculo 6,2, define sobreendeudamiento como "Ai fini del presente capo, per 'sovraindebitamento' si intende una situazione di perdurante squilibrio tra le obbligazioni assunte e il patrimonio prontamente liquidabile per farvi fronte, nonché la definitiva incapacità del debitore di adempiere regolarmente le proprie obbligazione".

${ }^{4}$ Bethmann-Hollweg, August von, Der römische Civilprozess (Bonn, 1865), pp. 316-320.

${ }^{5} \mathrm{TABB}$, Charles, The Historical Evolution of the Bankruptcy Discharge, en American Bankruptcy Law Journal, 3 (1995), pp. 5-10.

${ }^{6}$ Martin, Nathalie, The Role of History and Culture in Developing Bankruptcy and 
noción de insolvencia comprende la incapacidad de pago (para referir a algo más amplio y certero que la "cesación de pago"), sea de una persona natural o jurídica, el proceso concursal tiene por objeto que todos los acreedores sean satisfechos en sus intereses en forma colectiva e igualitaria proporcional a su crédito en la cuotaparte que le corresponde de ese patrimonio insuficiente ${ }^{7}$. A los efectos del equilibrio de intereses y la igualdad entre los acreedores en primer lugar se debe evitarque alguno de ellos sea totalmente satisfecho en su crédito a costa y desmedro de los restantes. En segundo lugar, debe preverse la posibilidad para el deudor diligente y predispuesto a cumplir (al menos con parte de sus obligaciones) le sea posible una adecuada condonación y renegociación cuyo final exitoso conduzca a una liberación total de deudas y un nuevo comienzo en su vida jurídico-financiera ${ }^{8}$.

Esta investigación se compone así de cinco partes de desarrollo (II-VI) y las conclusiones: donde primero (II) se exponen los rasgos generales de la evolución de los procedimientos concursales; siguen los aspectos relevantes a lo largo de una resumida mirada del Derecho romano caracterizado por la pluralidad y diversidad de alternativas frente al deudor en crisis de iliquidez actual o eventual(III); se prosigue con la relación honor, buen nombre e insolvencia desde Roma hasta el ius commune (IV); en la siguiente sección se trata la recepción y posterior desarrollo en la Edad Media hasta la Moderna (el centro serán las ciudades italianas del norte y las alemanas) (V), ello para demostrar la continuidad y el hilo conductor desde y con el derecho romano. Por último (VI), se refiere a algunos modelos contemporáneos de regulación de la insolvencia de personas naturales en perspectiva del derecho comparado y la continuidad histórica de los procedimientos, especialmente en sus consecuencias jurídico-económicas para el deudor y su relación con lo expuesto. El artículo termina con las conclusiones sobre las principales constataciones y la necesidad de regulación de la insolvencia de personas naturales (VII).

\section{RASGOS GENERALES DE LA EVOLUCIÓN HISTÓRICA}

DE LOS PROCEDIMIENTOS CONCURSALES

El Derecho romano disponía de una pluralidad de procedimientos no sistematizados e inorgánicos para la regulación del fenómeno de la

Insolvency Systems: The Perils of Legal Transplantation, en Boston College Int. Comp. Law Rev., 28 (2005), pp. 1-77.

${ }^{7}$ LEPA, Brita, Insolvenzordnung und Verfassungsrecht (Berlin, 2002), pp. 22-31.

${ }^{8} \mathrm{ZIEGEL}$, Jacob, Facts on the Ground and Reconciliation of Divergent Consumer Insolvency Philosophies, en Theoretical Inquiries, 7 (2006), pp. 299 у 304; TАв , Charles, Lessons from the Globalization of Consumer Bankruptcy, en Law Soc. Inq., 30 (2005) 4, pp. 763-782. 
concurrencia y el conflicto entre una pluralidad de acreedores frente a un deudor patrimonialmente en crisis (sea esta una incapacidad de pago, un sobreendeudamiento, o bien, una simple demora en el cumplimiento de sus obligaciones) $)^{9}$. El acreedor podía ejercer su derecho ya sea agrediendo al patrimonio o a la persona (incluso físicamente) del deudor, para lograr así la satisfacción de su crédito ${ }^{10}$. Podía acudirse a medidas que iban desde el simple arresto o aprehensión, la incautación de bienes o traslación del patrimonio, hasta la servidumbre o trabajo forzoso a servicio del acreedor e, incluso, la sumisión del deudor como esclavo y por ende enajenable en el mercado para obtención de liquidez.

El tratamiento de un deudor insolvente en la tardía Edad Media y comienzos de la Moderna sigue en Europa una serie de alternativas, reglas y principios generales comunes: cesión de bienes a los acreedores, trabajo forzado o servidumbre personal, arresto ya sea privado en dependencias del acreedor, o bien, en prisiones públicas para estos casos. Paralelo a estas medidas existía una sanción que a su vez desempeñaba un rol de medida de coerción (la infamia o vergüenza social del deudor). Este marco de alternativas instaban a familiares y amigos del insolvente a colaborar financieramente para evitar consecuencias más gravosas o para morigerar las sanciones ya aplicadas. Muchas de estas tenían un rol de publicidad a los efectos de que futuros contratantes puedan conocer, y así actuar con prudencia y prevención, frente a quién es o había sido insolvente ${ }^{11}$.

Un salto cualitativo en la historia del tratamiento de la insolvencia se dio en el período de las prósperas ciudades italianas del norte y su desarrollo comercial, lo que significó la recepción y comienzo de sistematización de las instituciones pensadas y heredadas del Derecho romano. Pero fue recién en el siglo XVII que se sistematizaría el Derecho concursal con cierta autonomía a partir de la necesidad de tratamiento especial de la insolvencia a partir de la contribución de Salgado de Somoza, que sirvió de base para la formulación y técnica legislativa de leyes ya concentradas en la materia ${ }^{12}$. Las raíces

${ }^{9}$ Levinthal, Louis Edward, The Early History of Bankruptcy Law (Pennsylvania, 1918), pp. 19-25.

${ }^{10}$ WENGER, Leopold, Institutionen des römischen Zivilprozessrechts (München, 1925), pp. 220-230.

${ }^{11}$ Spann, Michael, Der Haftungszugriff auf den Schuldner zwischen Personal- und und Vermögensvollstreckung. Eine exemplarische Untersuchung der geschichtlichen Rechtsquellen ausgehend vom römischen Recht bis ins 21. Jahrhundert unter besonderer Berücksichtigung bayerischer Quellen (Münster, 2004), pp. 55-57; cfr. la visión actual del consumidor sobreendeudado y su estigmatización, en Frade, Catarina, Bankruptcy, Stigma and Rehabilitation en ERA Forum, 13 (2012), pp. 45-57.

${ }^{12}$ ForSTER, Wolfgang, Konkurs als Verfahren: Francisco Salgado de Somoza in der Geschichte des Insolvenzrechts (Köln - Weimar, 2009), pp. 295 ss. 
históricas romano-canónico-germánicas del Derecho concursal demuestran una enorme similitud con los sistemas actuales en relación al tratamiento de la insolvencia de las personas naturales ("personal insolvency", "Verbraucherinsolvenzrecht", "Restschuldbefreiung, "faillite civile") en la identificación, el tratamiento y las consecuencias jurídico-económicas ${ }^{13}$. Una de las alternativas que tenía el acreedor era someter al deudor insolvente a servidumbre personal, quizás lo más "digno" y "humano" en evolución, comparado con otras posibilidades. Ello si se tiene en cuenta que en un período inicial de la historia él respondía in personam y no necesariamente con su patrimonio frente al acreedor ${ }^{14}$. También es cierto que la servidumbre personal, en muchos casos, implicó una "prisión privada" del deudor sometido a su acreedor, que sus costos elevados paulatinamente influyeron para que el naciente Estado asumiera con establecimientos públicos la privación de libertad de algunos deudores. Un logro importante para el acreedor como para el deudor significó el tránsito de la prisión privada (administrada y financiada por el acreedor) hacia la pública (gestionada y dentro de las potestades punitivas y coercitivas del Estado). Independiente de ello el resquicio de la responsabilidad in personam del deudor insolvente que sustentaba sin problemas la aplicación de la prisión por deudas (aún con el argumento de ser medida de coerción y no pena) duró hasta el siglo XIX. Es decir, respondía más allá y no obstante su patrimonio, lo que ciertamente tenía ya por sí un cariz de mácula social que de alguna forma justificaba el rol coercitivo (y punitivo) del Estado para con el insolvente. ${ }^{15}$.

La liberación, condonación o repactación deuda residual juega un papel importante en la actualidad en el Derecho concursal en general, y especialmente cuando se trata de insolvencia de personas naturales (o de consumidores ${ }^{16}$. El procedimiento tiene su punto de partida en un acuerdo entre el deudor y sus acreedores a partir del cual se sientan las bases para la reestructuración negociada de las deudas o el acuerdo con concesiones recí-

\footnotetext{
${ }^{13}$ Spooner, Joseph, Long Overdue, What the Belated Reform of Irish Personal Insolvency Law Tells Us About Comparative Consumer Bankruptcy, en American Bankruptcy Law Journal, 86 (2012), pp. 243 ss. y 298; JACOBI, Florian, Insolvenzrechtsreform zum Verfahren natürlicher Personen (Insbüro, 2012), pp. 123; PAPE, Gerhard, Verbraucherinsolvenz 2012. Gefühlter und tatsächlicher Reformbedarf, en ZVI (2012), pp.150.

${ }^{14}$ Treiman, Israel, Acts of Bankruptcy: A Medieval Concept in Modern Bankruptcy Law, en Harvard Law Review, 52 (1938), pp. 189-215.

${ }^{15}$ Finley, Moses, La servitude pour dette, en Revue Historique de Droit Français et Etranger, 43 (1965) 4, pp. 159-184; cfr. CoHEN, Jay, The History of Imprisonment for Debt and Its Relation to the Development of Discharge in Bankruptcy, en Journal of Legal History, 3 (1982), pp. 153, 157.

${ }^{16}$ Frind, Frank, Praxis-Prüfstand: Die Vorschläge zur Neuordnung des Insolvenzverfahrens natürlicher Personen, en ZinsO. (2012), p. 668.
} 
procas que delinea la responsabilidad del deudor de futuro (moratorium o concesión de plazos, suspensión de las ejecuciones singulares, condonación de intereses y condonación parcial de la deuda). Este acuerdo después es revisado y aprobado por una autoridad administrativa o judicial ${ }^{17}$. Por último, una parte (cuota o porcentaje) de los ingresos que perciba el deudor de futuro se pondrá a disposición de los acreedores para liquidar sus obligaciones ${ }^{18}$. Así durante un período de tiempo prolongado se irán satisfaciendo a los acreedores, quedando el deudor con el porcentaje de sus ingresos que le aseguren una vida digna a él y a su entorno familiar dependiente. Este modelo se corresponde al "Verbraucherinsolvenzrecht" (Derecho de insolvencia para consumidores) y al "Restschuldbefreiung" (procedimiento liberatorio; sobreseimiento en la antigua denominación, por deuda residual) como regulación de la insolvencia personal en Alemania. En realidad constituyen "una especie de ${ }^{19}$ ejecución patrimonial (sin dejar de afectar lo personal) que no difiere mucho en sus fines y en el cómo de la servidumbre personal del deudor a favor de su acreedor que existió en el Derecho romano, Edad Media y Moderna. Claro que en el cómo el deudor-consumidor del siglo XXI no está privado de su libertad o prestando un servicio en un horario predeterminado a favor del acreedor, sí destina obligatoriamente parte de sus ingresos en el tiempo para satisfacer a aquel ${ }^{20}$.

Solo como ejemplo, desde el año 2012, el Código de Insolvencia alemán fue parcialmente modificado para introducirle mejoras y flexibilidad en procedimientos concursales corporativos y para consumidores como etapas progresivas de mejora del sistema concursal en su conjunto. Una primera etapa se relaciona con mejorar las condiciones y acceso para la reorganización o saneamiento de la empresa en crisis; otra posterior comprende una mejora en tiempos y tratamiento de la insolvencia de personas naturales (con entrada en vigencia para julio del 2014) y que luego se describirá2 ${ }^{21}$. Así para

${ }^{17}$ ThOLE, Christoph, Vom Totengräber zum Heilbringer? Insolvenzkultur und Insolvenzrecht im Wandel, en JZ. (2011), pp. 765.

${ }^{18}$ Gratzer, Karl, “Introduction” a Gratzer, Karl - Stiefel, Dieter (editores), History of Insolvency and Bankruptcy from an International Perspective (Huddinge, 2008), pp. 5-14.

${ }^{19}$ THOLE, cit. (n. 17), pp. 765.

${ }^{20}$ Gratzer, cit (n. 20), pp. 5-14.

${ }^{21} \mathrm{http}: / /$ www.bmj.de/DE/Buerger/verbraucher/Insolvenzrecht/insolvenzrecht node.html: "[...] soll insolventen Existenzgründern und Verbrauchern schneller als bisher eine zweite Chance ermöglicht werden, wenn sie einen Teil ibrer Schulden sowie die Verfahrenskosten begleichen. Die Gläubiger profitieren ebenfalls von dieser Beschleunigung, weil die Schuldner einen gezielten Anreiz erhalten, möglichst viel zu bezablen. Darüber hinaus enthält der Gesetzentwurf Regelungen zur Verkürzung und Umgestaltung des Restschuldbefreiungsverfabrens, zur Stärkung der Gläubigerrechte 
und zur insolvenzrechtlichen Stellung von Mitgliedern von Wobnungsgenossenschaften. Auch sieht der Entwurf die Zulassung des Insolvenzplanverfahrens für Verbraucher zu - eine weitere Möglichkeit, dass sich Schuldner und Gläubiger im Insolvenzverfahren über die Regulierung der Verbindlichkeiten einigen" (Traducción libre: "Tanto para empresarios como para consumidores insolventes se permite una segunda oportunidad si pagan una parte de sus deudas y los gastos. Los acreedores también se benefician de esta aceleración, porque el deudor recibirá un incentivo específico para pagar lo más posible. Además, el proyecto de ley contiene disposiciones relativas a la reducción y reestructuración del proceso de alivio de la deuda restante, para fortalecer los derechos de los acreedores y el estado legal de insolvencia de los miembros de las cooperativas de vivienda. El proyecto prevé la autorización del procedimiento de plan de insolvencia para los consumidores - otra posibilidad de que algunos deudores y acreedores en el procedimiento de insolvencia sobre la regulación de los pasivos"). Véase también el Entwurf eines Gesetzes zur Verkürzung des Restschuldbefreiungsverfahrens und zur Stärkung der Gläubigerrechte. Drucksache 17/13535 (BT), 15.5.2013 ("Proyecto de ley sobre la reducción del proceso de liberación de deuda residual y el fortalecimiento de los derechos de los acreedores"): "Vor dem Hintergrund, dass die Dauer des Restschuldbefreiungsverfahrens seit dessen Einfübrung im Jahr 1999 umstritten und - isoliert betrachtet - im europäischen Vergleich verhältnismäßig lang ist, sieht der Gesetzentwurf die Möglichkeit vor, Restschuldbefreiungsverfahren vorzeitig bereits nach drei oderfünfJahren zu beenden, wenn die betroffenen Schuldner innerhalb der genannten Zeiträume eine Mindestbefriedigungsquote erfüllen oder zumindest die Kosten des Verfahrens tragen. Damit sollen auch bislang im Restschuldbefreiungsverfahren fehlende Anreize fürSchuldnergeschaffenwerden, sich in besonderem Maßeumeine Befriedigungder bestehenden Forderungen zu bemühen. Zugleich wird das Restschuldbefreiungsverfahren umgestaltet. Hierdurch werden Schwachstellen im geltenden Recht behoben und der Verkürzung des Rest- schuldbefreiungsverfahrens Rechnung getragen. Insbesondere werden verschiedene Maßnahmen zur Stärkung der Gläubigerrechte vorgeschlagen. Im Verbrau-cherinsolvenzverfahren soll der außergerichtliche Einigungsversuch gestärkt und statt des gerichtlichen Schuldenbereinigungsplanverfahrens die Möglichkeit eines Insolvenzplanverfahrens eröffnet werden, um die Einigungschancen zwischen Schuldner und Gläubigern zu erhöhen. Unter anderem empfieblt der Ausschuss, die im Gesetzentwurf vorgesehene Mindestbefriedigungsquote für die Abkürzung der Dauer des Restschuldbefreiungsverfahrens nach 5300 Absatz 1 Satz 2 Nummer 2 InsO-E von 25 auf 35 Prozent zu erhöhen und das gerichtliche Schuldenbereinigungsplanverfahren einschließlich der Zustim- mungsersetzung als notwendiges Verhandlungsinstrument neben der Zulassung des Insolvenzplanverfahrens in Verbraucherinsolvenzverfahren beizubehalten. Um den beteiligten Personenkreisen und insbesondere der gerichtlichen Praxis einen ausreichenden Vorlauf zu gewährleisten, wird das Inkrafttreten des Gesetzes im Wesentlichen auf den 1. Juli 2014 festgelegt" (Traducción libre: "Teniendo en cuenta que la duración del procedimiento para liberación de deuda residual desde su introducción en 1999, es polémico y comparativamente con otros países europeos relativamente largo, es que se prevé la posibilidad de poder acceder a la condonación luego de tres o cinco años, si los deudores interesados reúnen una cuota mínima en los plazos a satisfacer o por lo menos tienen satisfechas las costas del proceso. Por lo tanto, la falta de incentivos para que los deudores pueden instar un procedimiento 
la condonación de deuda residual se acota el plazo total de control de buena conducta de pago dentro del cual el deudor debe destinar un porcentaje de sus ingresos embargables para el pago de sus deudas. Si hasta la reforma el plazo total concedido al deudor para control de su buena conducta cumplidora de los pagos era de 6 meses ahora se reduce a la mitad siempre que haya satisfecho al menos el $35 \%$ del pasivo comprometido (hasta la reforma era un $25 \%$ ). Se disminuye el tiempo de rehabilitación del deudor acorde a los estándares de otros Estados y se exige simultáneamente siempre que exista un porcentaje mínimo de la deuda total satisfecho, resguardándose así los intereses de los acreedores ${ }^{22}$. La reducción del plazo tiene directa relación con la posibilidad del deudor para acceder a muchos bienes sociales, culturales y económicos. Su credibilidad y reputación para la obtención de aquellos bienes se mejora vencido ese plazo de control. En la misma linea de tratamiento de la insolvencia y sobreendeudamiento de personas naturales se pueden mencionar las recientes reformas italiana (mediante Ley del 27 de enero del 2012, n. 3).

Ciertamente el procedimiento impone una buena conducta del deudor medible en la retención forzosa de una cuota o parte de sus ingresos. Claro está también en una conducta cooperativa de transparencia patrimonial. Incluso las limitaciones a la que se encuentra sujeto del deudor durante ese período de control, en cierta forma afectan su libertad e igualdad como las

concursal donde tengan la posibilidad de obtener la liberación de su deuda residual, tiene una importancia expansiva en lo social y económico. En particular, las diversas medidas que se proponen buscan fortalecer los derechos de los acreedores, también mejorar la información para el consumidor en los procedimientos de insolvencia de renegociación para no acudir directamente a la liquidación. La posibilidad de un plan de insolvencia incentiva el aumentar las posibilidades de acuerdo entre deudores y acreedores. Entre otras cosas, el Comité recomienda pasar de un $25 \%$ a un $35 \%$ de monto saldado para aumentar la prevista en el proyecto de relación de satisfacción mínima legal para la abreviación de la duración del procedimiento de condonación de la deuda residual, según $\$ 300$ inc. 1 frase 2 número 2 Concursal E como herramienta de negociación necesaria, además la aprobación de las actuaciones del plan de insolvencia manteniendo ello para el tratamiento de la insolvencia de consumidores. Para garantizar a los grupos de personas, y en particular la práctica judicial implicó un suministro suficiente, la entrada en vigor de la ley es esencialmente la de julio de 2014"). Véase con mayor detalle: PAPE, Gerhard - Grote, Hugo, Das neue Insolvenzund Restschuldbefreiungsverfahren. Was die lange überfällige Reform bringt - und ob sie Sinn macht, en AnwBl (2012), pp. 507.

${ }^{22}$ Cfr. Hirte, Heribert, Stellungnahme zum Regierungsentwurf eines Gesetzes zur Verkürzung des Restschuldbefreiungsverfahrens und zur Stärkung der Gläubigerrechte (BT-Drucks. 17/11268) für den Deutschen Bundestag- Sitzung des Rechtsausschusses am 14. Januar 2013, 1-8 Disponible en: http://www.bundestag.de/bundestag/ ausschuesse17/a06/anhoerungen/archiv/36_Restschuldbefreiung/04_Stellungnahmen/Stellungnahme_Hirte.pdf;_OвERMÜLLER, Manfred, Kreditsicherheiten in der Verbraucherinsolvenzreform en ZVI. (2012), pp. 146 (visitado 1/1/2013) 
de su entorno, lo que lleva a algunos a hablar de una nueva modalidad de reclusión "virtual" o prisión de acceso a bienes y servicios del siglo $\mathrm{XXI}^{23}$.

\section{El DEREChO ROMANO Y EL DEUdOR INSOLVENTE:}

\section{EL LARGO CAMINO DESDE LA RESPONSABILIDAD PERSONAL A LA} PATRIMONIAL

La historia del Derecho romano se extiende por casi mil años desde el inicio de la República 510 a.C. hasta la codificación de Justiniano (528-534 d.C.) Durante esos siglos se fueron conformando diversos procedimientos (algunos que subsistieron paralelamente, otros que sustituyeron o modificaron a los más antiguos) aplicables para hacer efectiva la responsabilidad del deudor, sea en su persona, sea en su patrimonio, o en ambos ámbitos.

La ejecución, acudiendo a la responsabilidad y sanción personal, puede ser consideradoa como la más antigua de las vías ejecutiva. Sirvió para que el acreedor pudiera decidir sobre la suerte en la persona (y claro está, en el patrimonio insuficiente) del deudor. En eficiencia y económicamente pensado el deudor insolvente podía someterse a servidumbre personal y de esa forma trabajar para el acreedor pagando a lo largo del tiempo sus deudas ${ }^{24}$. O bien según las necesidades del acreedor disponía de la posibilidad de obtener liquidez inmediata ya que el deudor devenía en esclavo y por ende era enajenable en el comercio. El proceso correspondiente ya estaba en las XII Tablas (451 a.C.), fue dominado por un fuerte carácter punitivo: si el deudor, dentro de los 30 días judicialmente establecidos, no pagaba su deuda, el acreedor podía acceder a su custodia y control mediante la actio legis per manum iniectionem ${ }^{25}$.

1. Durante un período de transición de treinta días, el infortunado deudor podía acudir al préstamo o rescate económico de sus familiares, amigos o de otros bien dispuestos prestamistas. La intervención del pretor

${ }^{23}$ Laroche, Peter - Pruskowski, Wolfgang - Schöttler, Alexandra - SieBERT, Volker - VALlender, Heinz, Insolvenzrechtsreform 2. Stufe - die geplanten Änderungen in der Insolvenz natürlicher Personen, en ZIP. (2012), p. 558; Stephan, Stellungnahme zum Referentenentwurf eines Gesetzes zur Verkürzung des Restschuldbefreiungsverfahrens, zur Stärkung der Gläubigerrechte und zur Insolventfestigkeit von Lizenzen, en $Z V I$. (2012), p. 85.

${ }^{24}$ Mitteis, Ludwig, Über das Nexum, en Zeitschrift der Savigny-Stiftung, rom. Abt., 22 (1901), pp. 96 ss.; KROPPENBERG, Inge, Die Insolvenz im klassischen römischen Recht (Köln, 2001), pp. 10-15. Esta autora se refiere a la ley de insolvencia como un "factor de inseguridad"(p. 10).

${ }^{25}$ Behrends, Okko, Der Zwölftafelprozeß: zur Geschichte des römischen Obligationenrechts (Göttingen, 1974), pp. 35-67. 
garantizaba que el destino de ese préstamo fuese el de pagar una deuda. Después de 60 días adicionales, y con las declaraciones repetidas del deudor ante el pretor sobre la imposibilidad de pago, aquel podía ser vendido como esclavo o incluso ejecutado físicamente. Las partes del cuerpo que quedaban simbolizaban la cuota-parte que era distribuida entre los acreedores ${ }^{26}$. En este primer momento de desarrollo parecen ser estos los únicos procedimientos disponibles. Sólo después de varios años, el deudor insolvente podía, en notable inferioridad de condiciones y bajo la sujeción de su acreedor (addictio debitoris), intentar o proponer una negociación. El addictus no tenía el estatus de esclavo, sino que era un hombre libre y capaz, lo que permitía acordar una prórroga y modalidad de pago con su acreedor y así poder ser liberado de esa condición ${ }^{27}$.

Estos derechos de decisión absoluta y extrema que gozaban los acreedores fueron abolidos en el año 313 a.C. por la Lex Poetelia. Desde entonces, se perfeccionó y quedó institucionalizada la servidumbre personal por deudas. De esta forma el deudor trabajaba forzosamente para el acreedor (tenía cierta limitación a su libertad personal), pero permitía que en el transcurso del tiempo pudiera pagar sus obligaciones. No está claro si la servidumbre personal por deudas también fue abolida después de un cierto tiempo, o si ello aconteció de facto o desuetudo ${ }^{28}$. En el período de la República surge la posibilidad de su sustitución por un derecho real de garantía (hipoteca) de carácter voluntario (nexum) ${ }^{29}$, sobre la persona del mismo deudor, o bien, otorgada por un tercero de modo que la manus iniectio recaía sobre un bien afectado a esa obligación. Como resultado, se disponían de varías alternativas para el acreedor que excluían la ejecución física o muerte del deudor $: i$ ) El acreedor podía someter a esclavitud a su deudor y, siendo una cosa, era intercambiable y liquidable en el mercado; ii) El negocio denominado nexum ${ }^{30}$, que para su debida publicidad, era acompañado de una lujosa ceremonia, incluyendo el peso de las materias primas como el cobre en presencia de

${ }^{26}$ Kroppenberg, cit. (n. 24), pp. 252-254.

${ }^{27}$ Solazzi, Siro, Studi sul concorso dei creditori nel Diritto romano, en Atti della R. Accademia dei Lincei, 36 (1920), pp. 545-580.

${ }^{28}$ Bressler, Steffen, Schuldknechtschaft und Schuldturm. Zur Personalexekution im sächsischen Recht des 13.-16. Jahrbunderts, (Berlin, 2004), pp. 166-170.

${ }^{29}$ Rodríguez Otero, Lino, El enigmático "nexum" como precedente de la hipoteca, en Revista Crítica de Derecho Inmobiliario, 677 (2003), pp. 1.619-1.692.

${ }^{30}$ WAgner, Herbert, Die Entwicklung der Legalhypotheken am Schuldnervermögen im römischen Recht (bis zur Zeit Diokletians) (Köln, Wien, 1974), pp. 12-34; Nicosia, Giovanni, La "manus iniectio": dal regime originario a quello della "manus iniectio pura”, en Praesidia libertatis. Garantismo e sistemi processuali nell' esperienza di Roma repubblicana. Atti del VI Convegno di Copanello, 7-10 giugno 1992, en Silloge. Scritti 1956-1996 (Catania, 1998), II, pp. 637-668 
cinco testigos. Esto no era necesario para la validez del negocio, sino sólo una forma de forma de publicidad del acto ${ }^{31}$. El origen de la actio estaba solo en el contrato y al parecer tenía menos connotación penal que el procedimiento judicial del iii) addictus, en el cual el deudor estaba en cautiverio durante un período limitado de tiempo para negociar por sí o instar, como medida coercitiva, que un familiar o amigo se apiadare ${ }^{32}$.

Con el tiempo los métodos más duros y que afectaban la libertad y dignidad del deudor no fueron más tolerados en el tiempo: una multitud enfurecida marchó hacia el Foro - la Curia- para exigir que el Senado hiciera cambiar la ley. Así el nexum se convertiría en un negocio de prestación de servicios (el que no perdía de hecho su carácter ciertamente de servidumbre personal) al que se sumaba una garantía real de la deuda conformada por los bienes pignorados (propios del deudor, de su familia, o bien, entregado por terceros) $)^{33}$.

2. Desde aproximadamente el siglo II a.C., se desarrolló un procedimiento que guarda una similitud con algunos sistemas contemporáneos cuando la incapacidad de pago del deudor no le es imputable. Bastaba algo más simple que la insolvencia (sea incapacidad, cesación de pagos o sobreendeudamiento), la sola exigibilidad de la obligación ${ }^{34}$. El acreedor podía así solicitar la liquidación de los activos necesarios por ante el magistrado mediante la venditio bonorum. Ello se publicaba en un edicto del pretor y se procedía a la designación del curator bonorum que podría ser designado como sujeto fiduciario de los bienes ${ }^{35}$. Recién más tarde se modificaría este procedimiento, mediante un decreto pretoriano, que permite un acceso y agresión directa a los bienes del ejecutado sin tantos intermediarios. El proceso se inicia con la solicitud de un acreedor ante el pretor o gobernador, quienes por un decreto declaran admisible la petición y al mismo tiempo ordenan la confiscación de los bienes del deudor, era ahora directamente el pretor quien gestionaba la custodia y administración de los activos (missio in possessionem) o su enajenación (missio in bona), ello lo hacía en beneficio de todos los acreedores cuyos derechos se habían hecho valer ${ }^{36}$. La determinación exacta de los acreedores y sus dere-

\footnotetext{
${ }^{31}$ Kroppenberg, cit. (n. 24), pp. 259-265.

${ }^{32}$ Solazzi , cit. (n. 27), pp. 550.

${ }^{33}$ Mac Cormack, Geofrey, "Nexi", "iudicati" and "addicti" in Livy, en Zeischrift der Savigny-Stiftung, 84 (1967), pp. 350-354.

${ }^{34}$ PePpe, Leo, Studi sull esecuzione personale, I: Debiti e debitori nei primi due secoli délia repubblica romana (Milano, 1981), pp. 23-35.

35 Triandafil, Ernest, Histoire des voies d'exécution en droit romain. Époque des actions de la loi de la procédure formulaire (Paris, 1914), pp. 25-56.

${ }^{36}$ Weiss, Egon, “Missio in possessionem”, en Paulys Realencyclöpadie der classischen Altertumswissenschaft, 15 (München, 1980) 2, pp. 2054- 2057.
} 
chos se anunciaba como publicidad mediante la proscriptio. Los acreedores se comprometían así a nombrar un bonorum magister para la realización y liquidación de los bienes como una universalidad mediante su cesión ${ }^{37}$. El adquirente cesionario (bonorum emptor) es un sucesor universal inter vivos del deudor y debe pagar, como contraprestación por el patrimonio que adquiere, poniendo ello a disposición de los acreedores. La etapa de distribución entre los acreedores depende del acuerdo entre estos rigiendo la regla del trato igualitario, según su cuota parte (par conditio omnium creditorum). Los privilegios y preferencias se tienen en cuenta antes de determinar la porción a distribuir entre los acreedores valistas o quirografarios. En caso que los bienes se encontraran en varias provincias, se nombraban varios fideicomisarios. Después de un período de al menos treinta días, se efectuaba la transferencia por el magister curatorum al mejor postor. Si aún el patrimonio del deudor resultaba insuficiente para cubrir sus deudas, continuaba siendo responsable por el monto insoluto y quedaba liberado en relación a lo satisfechos ${ }^{38}$.

La venditio bonorum, en general, fue un gran avance: no sólo proporcionaba una mejor garantía y satisfacción a los acreedores, sino que también respetaba más la dignidad del deudor quien respondía con su patrimonio y no con su persona ${ }^{39}$. Sin embargo, tenía una desventaja para el deudor que era muy gravosa y que en sus efectos les generaba de hecho limitaciones serias: se afectaba su honra y la reputación (infamia), especialmente si quedaban deudas pendientes ${ }^{40}$. Los efectos se traducían en una verdadera exclusión del acceso al crédito eventualmente para una asistencia financiera que pudiera liberarlo de la totalidad de las obligaciones pendientes. Era, además, un estigma significativo para un ciudadano romano, una deshonra comparable con una capitis deminutio ${ }^{41}$.

La siguiente etapa de desarrollo del derecho romano estará marcada por la muerte de Cayo Julio César en el 44 a.C.: inestabilidad social, política y la guerra civil. ¿Cuál era la relación entre el manejo y gestión de las deudas que abrumaban a la aristocracia romana, la insolvencia, la infamia y los

${ }^{37}$ Purpura, Gianfranco, La pubblica rappresentazione dell insolvenza. Procedure esecutive personali e patrimoniali al tempo di Cicerone: Convegno "Lo spettacolo della giustizia a Roma: le orazioni di Cicerone" (Palermo, 2006), pp. 1-13.

${ }^{38}$ D'Amati, Laura, “Curator bonorum": una rilettura, en Bullettino dell Istituto di Diritto Romano “Vittorio Scialoja”, 33-34 (1991-1992), pp. 440- 448.

${ }^{39}$ CARrelli, Edoardo, Ancora sull origine della “bonorum venditio", en Studia et Documenta Historiae et Iuris, 10 (1944) 2, pp. 302-316.

${ }^{40}$ GIUfFrè, Vicenzo, Sull origine della "bonorum venditio" come esecuzione patrimoniale, en Labeo, 39 (1993), pp. 317-364.

${ }^{41}$ KASER, Max, "Infamia" und "ignominia" in den römischen Rechtsquellen, en Zeitschrift der Savigny-Stiftung, 73 (1956), pp. 220 ss.; Greenidge, Abel Hendy Jones, "Infamia". Its Place in Roman Public and Private Law (Oxford, 1894), pp. 15-25. 
procedimientos de ejecución antes descriptos? Para una respuesta inicial se debe comprender a la sociedad romana de entonces, quizás, mediante estas tres características: el concepto de la vergüenza social y deshonra, el alto costo de mantener la imagen pública en uno del nivel socio-económico y finalmente los requisitos de acceso a cargos públicos y la conformación de las elites mediante un entramdocursus honorum. La posibilidad de ascenso social estaba relacionada con el poder económico del candidato, lo que permitía no solo cubrir deudas personales, sino también convertirse en prestamista para tener no solo deudores, sino también fieles seguidores. Las inversiones en las actividades para la turba, como los circos y sus espectáculos precisaban de esclavos o de servidores personales. El inicio de alguno de los procedimientos mencionados aparejaban la deshonra pública y consecuente óbice para el ascenso, y por ende la cadena de deudas convertía todo en una congestionada burbuja financiera ${ }^{42}$.

3. Al comienzo del período imperial, se implementa un nuevo procedimiento: cessio bonorum. La Lex Iulia de bonis cedendis debe ser considerada con razón como la precursora de la mayoría de nuestras modernas leyes concursales y de insolvencia. No se sabe con certeza si esta reforma tuvo lugar poco antes o poco después del asesinato de Julio César ${ }^{43}$. A diferencia de los otros procedimientos este puede comenzar a instancias y decisión voluntaria del deudor. Además, se suma a ello el especial resguardo que tendrá la honra y buen nombre de éste, ya que justamente la cessio bonorum evita la infamia. En consecuencia, aquella conllevó un cambio histórico en las relaciones entre deudores y acreedores y un equilibrio entre sus intereses por el juego combinado de incentivos. Por su parte el deudor se obligaba a transferir sus bienes al acreedor voluntariamente. Esto daba lugar a la liberación del deudor sin las consecuencias de la mácula social y conservando su honor intacto. El procedimiento es esencialmente lo contrario de la venditio. La aplicación de cessio bonorum fue desde su inicio limitada en su ámbito de aplicación y con el correr del tiempo también se dejó de emplear ${ }^{44}$.

${ }^{42}$ Ioannatou, Marina, Affaires d'argent dans la correspondance de Cicéron en L'aristocratie sénatoriale face à ses dettes (Paris, Diss. Université de Paris II, 2006), I, pp. 50-7; II, pp. 260 ss.; Ducos, Michèle, La crainte de Pinfamie et l obéissance à la loi. (Cic, De Rep., V. 4. 5), en Revue d'Études Latines, 57 (1979), pp. 145-165.

${ }^{43}$ Longo, Giannetto, "Lex Iulia de cessione bonorum", en Novissimo Digesto Italiano, 9 (1963), pp. 810; Frederiksen, Martin W., Caesar, Cicero and the Problem of Debt, en Journal of Roman Studies, 56 (1966), pp. 128-141.

${ }^{44}$ Soza, María de los Ángeles, El “bonorum emptor”: su posición jurídica. Sumario. Procedimiento concursal. La posición jurídica del "bonorum emptor" (Madrid, 2008), pp. 147-149. 
Un tercer momento importante en la evolución de la regulación de la insolvencia en el derecho romano fue la introducción de distractio bonorum, concentrada a los activos del deudor y no a la universalidad de su patrimonio ${ }^{45}$. Este procedimiento se llevó a cabo originalmente sólo en casos excepcionales en los que las personas gozaban de protección y beneficios especiales: por ejemplo, con pequeños herederos del deudor y de los miembros de la aristocracia senatorial. En otros casos, el distractio probablemente pudo ser aplicada por el acuerdo entre los acreedores ya que no acarreaba consecuencias ni de libertad personal, ni infamia contra el deudor ${ }^{46}$. En lugar del magister interviene y asume el rol de curator directamente el pretor, él es responsable por la conservación e integridad de los bienes afectados. Al igual que en muchos procedimientos concursales modernos el deudor debe acreeditar su buena fe, es decir, que no está dolosamente insolvente ni que acude a este proceso de manera fraudulenta. Ello, ya que en el examen de admisibilidad del procedimiento el magistrado podía rechazarlo mediante un trámite sumario por el que se verificaba la existencia de fraude ${ }^{47}$.

\section{El PAPEL QUE DESEMPEÑABA EL BUEN NOMBRE (“EXISTIMATIO”) DESDE ROMA HASTA EL "IUS COMMUNE": "DigNitAS ET INFAMIA"}

1. El deudor insolvente no sólo estaba sujeto en su persona o con su patrimonio a la voluntad del acreedor, en mayor o menor medida, según los tipos de procedimientos ya descritos. Ellos tuvieron ciertas réplicas procedimentales luego en el ius commune. La duplicidad de tratamiento a la crisis del deudor, civil y penal, acarreaba un daño o sanción colateral: la afectación al nombre y a la honra que limitaba su desarrollo socio-económico y el de su familia. La calidad de insolvente era de hecho equivalente al fraude, hurto o aprovechamiento y obtención de lo ajeno ${ }^{48}$. Fue retratado ello en la Edad Media europea con el concepto romano de fallitus commune cogens, fraudator ergo ("el deudor insolvente implica el fraude"). Por ello el orgullo, ostentación, la falta de honestidad y conductas especulativas, fueron vistos a menudo como indicios previos a los

${ }^{45}$ SPANN, cit. (n. 11), pp. 41-43;

${ }^{46}$ WLassaK, Moritz, "Cessio bonorum", en Paulys Realencyclopädie der classischen Altertumswissenschaft (Stuttgart, 1899, 1970), III,2, 1995-2000; Woess, Friedrich von, Personalexekution und "cessio bonorum" im römischen Reichsrecht, en Zeitschrift der Savigny-Stiftung, rom. Abt., 43 (1922), pp. 485-529.

${ }^{47}$ Giuffrè, Vicenzo, La c. d. "lex Iulia de bonis cedendis", en Labeo, 18 (1972), pp. 173-191.

${ }^{48}$ Io annatou, Marina, Le code de l honneur des paiements. Créanciers et débiteurs àla fin de la République romaine, en Annales. Histoire, Sciences Sociales, 6 (2001), pp. 1201-1221. 
procesos concursales. Los deudores fueron sometidos por el ordenamiento jurídico de un tratamiento sancionatorio que incluía finalmente a quiénes no querían -fraudulentamente- y a los que no podían - sin culpa alguna- pagar sus deudas. También para los deudores “honestos” existían en este contexto, extrañas y humillantes ceremonias que garantizaban la publicidad del estado de insolvente y su carencia de honor. La siguiente declaración de Baldus se puede considerar como un lema apropiado: "fallitus, ergo fraudator" ("fallido, por lo tanto defraudador"). No está claro en qué momento este juicio se transformó en una presunción que acompañaba al insolvente como quizás, una de las peores sanciones. En otras palabras siempre que había insolvencia, pues existía fraude (fraus). A ello se agregaba la deshonra o infamia en tanto: "falliti sunt infame" Los orígenes reales de la infamia deben inquirise en el derecho canónico y están en conexión estrecha con las llamadas irregularidades o inhabilidades generales del Derecho romano (especialmente en la República) y sólo pueden entenderse en este contexto. La infamia era lo contrario de dignitas, y esta a su vez era un atributo o "bien" de todo ciudadano romano. Esta era una mezcla compleja de bien nacido, riqueza, contribución cívica a la comunidad y el mérito individual ${ }^{50}$. La "fama" no era un término legal, sin embargo, se fundaba en un término jurídico: la existimatio (buen nombre) ${ }^{51}$.

2. Los cargos públicos en la Roma Republicana no eran nominalmente

${ }^{49}$ Whitman, James Q., The Moral Menace of Roman Law and the Making of Commerce: Some Dutch Evidence, en Yale Law Journal, 105 (1996), pp. 1841, 1871: “To European authors everywhere in the seventeenth century, the declaration of bankruptcy was the single most scandalous phenomenon of commercial society ... all of whom regarded the declaration of bankruptcy as a ghastly evil [...] a German pamphleteer of 1619 describing the reaction in the community of a bankruptcy filing as follows: Once word of this makes the rounds and becomes known, the average man bursts out with imprudent, violent and angry words. He storms, curses, blasphemes, says scandalous and contemptuous things about debtors, denouncing them as rogues, thieves and men without honor [...]".

${ }^{50}$ FORSTER, cit, (n. 12), pp. 3-17; cfr. YAvetz, Zvi, "Existimatio", "fama" and the Ideas of March, en Harvard Studies in Classical Philology, 78 (1974), pp. 35-65.

${ }^{51}$ Löвmann, Benno, Der kanonische Infamiebegriff in seiner geschichtlichen Entwicklung unter besonderer Berücksichtigung der Infamielehre des Franz Suarez (Leipzig, 1956), pp. 134: "Beide Begriffe sind in ibrer Struktur wesentlich verschieden. Bei der Rezeption der römischen Infamie hat das kanonische Recht seinen Fama-infamia-Begriff als Grundlage beibehalten und versucht, ihm den Begriff der existimatio einzugliedern. Damit erfuhr der Begriffsinhalt des defectus famae eine kleine Veränderung: War bisher der defectus famae eine Irregularität sine culpa, so wurde jetzt daraus eine Irregularität ex culpa, die Infamie bestand jetzt im Verlust des guten Rufes auf Grund einer sittlichen Schuld, in der Regel eines crimen manifestum. Die infamia criminalis gab ibre Stellung an den defectus famae ab, Infamie im eigentlichen Sinne wurde jetzt der defectus famae". 
remunerados, no obstante el acceso a ellos sentaba la base para una carrera cursus honorum, que se identificaba, suponía y a la vez denotaba dignitas. Sin este presupuesto era imposible el acceso a cargos superiores como el prefecto del pretorio o el tribunado, así como miembro del Senado. Pero la posesión de estos cargos no tenía, sino una indirecta relación con existimatio ciudadano (honestidad, digno de la fe pública). Lo que tenía enorme importancia era su riqueza: así para calificar y poder aspirar al Senado, debía disponer de un patrimonio de al menos 400.000, con el peso que ello estaba controlado y en caso de no disponer de ese patrimonio estaba sujeto a censura ${ }^{52}$. Por esa razón no era infrecuente que los aristócratas romanos obtuvieran préstamos de sumas cuantiosas para financiar su carrera, sea entre ellos, o bien, de prestamistas profesionales. Era frecuente que obras como el circo romano y sus actividades, como así también otras de corte populista servían para granjearse el apoyo popular y poder recuperar liquidez para el pago de los créditos. Otro medio empleado eran sobornos o incluso entrar en relación con familias romanas ambiciosas e influyentes, incluso mediante conformación de una nueva familia por el matrimonio. Durante las últimas décadas de la República, una carrera política era extremadamente costosa, aunque la propia deuda generada por los préstamos no eran moralmente reprobables ${ }^{33}$. Era un círculo vicioso donde los aristócratas ambiciosos se esforzaban constantemente y sus deudas impagas eran refinanciadas o sujetas a alguna moratoia, lo que impedía se afecte su honra ${ }^{54}$.

3. Estas deficiencias morales o jurídicas denotaban irregularidades de la persona, terminología que se verá luego afianzada en el derecho canónico con la infamia. El resultado era el mismo: desplazar o impider que ciertos ciudadanos puedan acceder a determinados cargos por no ser dignos de ellos. Así no solo las

${ }^{52}$ Di Salvo, Settimio, La “lex Laetoria”, minore età e crisi sociale fra il III e il II sec. a.C. (Napoli, 1979), p. 205.

${ }^{53} \mathrm{Cfr}$. WACke, Andreas, Athleten als Darlehensnemer nach römischen Recht, en Studia et Documenta Historiae Iuris, 44 (1978), pp. 439-452. De hecho fue la continuación o refinanciamiento habitual de un amigo o cercano. Las cartas de Cicerón contienen varias referencias a sus deudas y a su esfuerzo por obtener activos y liquidez. Con ello pudo cumplir sus compromisos o compensar sus deudas mediante financiamiento. Una descripción detallada se encuentra en Ioannatou, cit. (n. 42), pp. 260-295; cfr. Purpura, cit. (n. 37), pp. 2-10.

${ }^{54}$ Frederiksen, cit. (43), pp. 127-130. Un buen ejemplo es el de Julio César. César obtuvo varios préstamos de otros nobles, sobre todo de Marcus Licinius Crassus, con el fin de financiar los juegos y el circo. Más tarde se le ofreció a César un soborno de parte de sus rivales políticos. Dicho soborno fue ofrecido en forma de pago de sus deudas para que pudiera optar al cargo de pontifex maximus a cambio de su candidatura. Sin necesidad de ello César pudo obtener financiamiento de otras fuentes y por cierto resultó igualmente electo en el año 62 a.C. 
conductas penales, sino un abanico más amplio afectaban como causales de inhabilidad el cursus honorum: una mácula que los convertía en inadecuados para el cargo, independiente de consideraciones relacionadas con la culpabilidad. En la práctica, independiente de si era o no una conducta penal, a los efectos de la honra necesaria para acceder al cargo tenían la misma fuerza excluyente. Esto explica porqué la infamia inicialmente tuvo tintes punitivos en la Edad Media temprana: se hablaba así de infamia criminalis que refería a cualquier conducta (privada o pública) con carácter penal. Sin embargo, la defectusfama necesariamente debía ser una conducta pública, o si sequiere, necesitaba de una infamia criminalis que trascienda lo secreto 55 . "Ambos se comportan como causa y efecto: La infamia criminalis es la causa de la defectus famae y esta es solo consecuencia de aquella, o como las antiguas fuentes enuncian, el defectus famae es esa cicatriz que queda de los crímenes". En un desarrollo posterior ambos conceptos se fusionaron para dar lugar a un único de infamia, solo diferenciable por el nivel de gravedad de un caso público versus otro secreto" ${ }^{56}$.

\section{DeRecho Estatuario NORditálico y de las CIUdAdes}

ALEMANAS DURANTE LA EDAD MEDIA HASTA LA MODERNA

Después de la caída del Imperio Romano de Occidente (año 476 d.C.) el caos de combinación, recepción mayor o parcial, con el derecho bárbaro hacen difícil una sistematización de los procedimientos destinados a la insolvencia de personas naturales durante la Edad Media. Por ello me centraré en los dos ejemplos más influyentes para el desarrollo posterior en Europa como fueron los derechos estatuarios de las ciudades italianas del norte con influencia fuerte del derecho longobardo y algunas ciudades alemanas. En el reino de los francos, en todo caso, cada comunidad aplicó su propio derecho, acudiéndose al derecho romano, cuando de personas de otras provincias se trataba, como el derecho común aplicable al extraño a la comunidad. Tras la división del Imperio entre los hijos de Carlomagno en Verdun (a. 843), no hubo cambios significativos en los procedimientos heredados de Roma. Se usaban varios tipos de procedimientos, desde la confezcación del patrimonio del deudor hasta resabios de la servidumbre personal combinada con el otorgamiento de garantías por el saldo insoluto. En el siglo XII se produjo en Europa un florecimiento económico, social y espiritual. En particular, el creciente papel de las ciudades y el comercio a larga distancia en este período fueron el caldo de cultivo de muchos instrumentos mercantiles y claro de la formulación de los títulos ejecutivos diferentes a una decisión judicial, el surgimiento del procedimiento monitorio y varias

\footnotetext{
${ }^{55}$ LÖBMANN, cit. (n. 51), pp. 11-14.

${ }^{56}$ Ibíd., pp. 15.
} 
reformulaciones al derecho concursal para adecuarlo a las prácticas comerciales emergentes, fundadas en la confianza, celeridad de la transacción, garantía, conformación de comunidades o cooperativas y control cruzado de solvencia ${ }^{57}$.

\section{La insolvencia y los procesos concursales en la Italia medieval del norte.}

Desde el siglo XIII se intensifica la influencia del derecho romano en la regulación de la insolvencia. Sí se establecen límites para la servidumbre personal por deudas, sólo un deudor que pudiera demostrar que era insolvente sin culpa podía ser eximido de ella. El castigo de los deudores fraudulentos (penalmente un delito) varía entre cada una de las ciudades y depende de circunstancias particulares ${ }^{58}$. En muchas ciudades, la transferencia voluntaria de bienes al acreedor (cessio bonorum) estaba totalmente excluida. La aplicación del Derecho penal y el estigma moral del deudor eranparte del procedimiento de quiebra. Tenía cierta publicidad, lo que era visto como muestra del funcionamiento de la sanción, y el arrepentimiento del fallido, por ende, considerable como un requisito previo para la recuperación económica del deudor sancionado en el norte de Italia medieval ${ }^{59}$. Para los miembros de las redes y asociaciones (corporaciones medievales) la quiebra de un miembro individual implicaba una afrenta que no solo afectaba al fallido, sino que se extendía a la credibilidad y éxito comercial de todos en sus actividades. Por ello el control de policía económica que ejercían las corporaciones con sus miembros y entre ellas era importante ${ }^{60}$.

La reputación de una persona en el comercio internacional y la regulación de la insolvencia son características básicas del derecho concursal en la Italia nórdica medieval y moderna. Una alternativa procedimental empleada para evitar la quiebra o liquidación de bienes del insolvente fue el acuerdo de repactación (moratoria, condonación de intereses, la refinanciación), los que tenían una regulación en sus condiciones y formas según las normas locales específicas ${ }^{61}$. El problema fundamental de los convenios estaba dado en el peso estratégico de los acreedores con privilegios que podían llegar a decidir

${ }^{57}$ Santarelli, Umberto, Per la storia del fallimento nelle legislazioni italiane dell età intermedia (Padova, 1964), pp. 25 ss.; Forster, cit, (n. 12), pp. 6-11.

${ }^{58}$ TAEUBER, Walther, Geld und Kredit im Mittelalter (Berlin, 1933), pp. 20-38; STrÄTZ, Wolfgang, Beiträge und Materialien zur Entwicklung von "Treu und Glauben" in deutschen Privatrechtsquellen vom 13. bis zur Mitte des 17. Jabrhunderts (Paderborn, 1974), I, pp. 25-33.

${ }^{59}$ Bonini, Roberto," La carcere dei debitori": linee di una vicenda settecentesca (Torino, 1991), pp. 15-32.

${ }^{60}$ SANTARELli, cit. (n. 57), pp. 56 ss.

${ }^{61}$ Cassandro, Giovanni, Le rappresaglie e il fallimento a Venezia nei secoli XIII e XIV con documenti inediti (Torino, 1938), pp. 15-24; cfr. Forster, cit, (n. 12), pp. 6-11. 
la suerte de aquellos sin limitación alguna ${ }^{62}$. La liquidación y subasta de los bienes del deudor se llevaba a cabo mediante un proceso ritual especial que existió durante toda la Edad Media hasta entrado el siglo XVIII variando en sus componentes. La simbología era importante para la publicidad, así la subasta de activos se determinaba en el tiempo, según una fecha que expiraba conforme se consumía una vela encendida en comienzo del procedimiento y que indicaba el precio máximo del bien ${ }^{63}$.

También existía la posibilidad de una cesión o transferencia voluntaria de los activos del deudor a los acreedores. Con ello el deudor se liberaba de las obligaciones que alcanzaban a pagarse con los activos liquidados, pero no se eximía de responsabilidad por la deuda insoluta. Ella sería cancelada con todo aquello que adquiriera de futuro como capital o ingresos, descontando un monto mínimo para su subsistencia ${ }^{64}$. Sin embargo, incluso esta transferencia voluntaria del deudor y su conducta colaborativa posterior no lo liberaba de cierta pérdida de reputación, que era quizás mucho más importante en la economía medieval para emprender y mantener las actividades. El deudor comerciante pertenecía a una corporación de pares y su buen nombre efectaba a los restantes miembros ${ }^{65}$. Por ello era necesaria la publicidad y exteriorización del arrepentimiento mediante ritos especiales. Así, en el caso de la cesión voluntaria, en algunas ciudades era acompañado de exigencias humillantes que ponían a prueba el honor del deudor. Por ejemplo, en Florencia se montaba un cartel en frente de la casa del deudor que indicaban sus datos personales, profesión y su condición de insolvente ${ }^{66}$. En Padua, por su lado, fue la plaza principal de la ciudad donde el deudor debía manifestar a viva voz y públicamente su decisión de transferencia de activos. De hecho se generaba una infamia que era muy compleja de ser borrada de la sociedad a la que pertenecía y en la que se desenvolvía el deudor ${ }^{67}$. El buen nombre y la oportunidad en los mercados medievales se fundaba

${ }^{62}$ Manzini, Vicenzo, La bancarrota e la procedura fallimentare nel Diritto veneziano, con cenni sui grandi fallimenti del secolo XV , en Atti del Reale Istituto Veneto di Scienze, Lettere ed Arti, 85 (1926), pp. 1093-1135.

${ }^{63}$ Forster, cit. (n. 12), pp. 10 ss.

${ }^{64}$ Ibíd., pp. 11-13.

${ }^{65}$ Manzini, cit. (n. 62), pp. 1.100.

${ }^{66}$ Pertile, Antonio, Sotoria della procedura (continuazione), en Storia del Diritto italiano dalla caduta dell impero romano all codificazione (Bologna, 1966), VI,2, pp. 385-395. Los mandamientos legales locales de los estados del norte de Italia se reservaban disposiciones especiales sobre la capacidad de pago y sus consecuencias negativas durante la realización de determinados ritos como conductas exigibles de la ejecución a los efectos de la publicidad.

${ }^{67}$ SANTARELLI, cit. (n. 57), pp. 56. En el norte de Italia se hizo públicamente conocida la transferencia de activos y a este respecto, la voluntad del deudor insolvente. Esto 
esencialmente en el crédito, que justamente resultaba lesionado no solo por el hecho de la transferencia de activos que efectuaba el deudor, sino además de las modalidades solemnes mediante las cuales se daba publicidad a ello ${ }^{68}$. Si a ello se le suma el rol fuerte y director de la insolvencia que tenían los acreedores, es fácil imaginar la exclusión de hecho del deudor para desempeñarse mercantilmente, no obstante haya podido en el transcurso del tiempo pagar la totalidad de sus deudas ${ }^{69}$.

Los procedimientos mencionados fueron también receptados en el sur de Francia con similares consecuencias socio-económicas ${ }^{70}$. El procedimiento concursal español ya sufriría importantes cambios en el siglo XVII como consecuencia de la crisis económica de la aristocracia y deudas de las distintas comunidades y la Corona. Combinó la transferencia de los activos y la prisión por deudas del insolvente, lo que podía evitarse con la voluntad del deudor manifestando la transferencia de activos en beneficio de sus acreedores ${ }^{71}$. De hecho, podría liquidar sus obligaciones durante un largo plazo con lo que adquiriera en el futuro y ello revestía una importancia estratégica. Los créditos podían tener un mejor resguardo si había un deudor común que ofreciera mejores garantías. Finalmente se existía un procedimiento fundado en la iniciacita del deudor por el cual declaraba su voluntad de pago frente al juez y reconocía sus obligaciones, juramentaba el detalle de su patrimonio y

fue asociado con la exposición pública del deudor: éste se debía sentar con las nalgas desnudas sobre una piedra.

${ }^{68}$ GLORIA, Andrea, La pietra del vituperio nel salone di Padova (Padua, 1851), pp. 5-30.

${ }^{69} \mathrm{PACE}$, Giacomo, Contrainte par corps: L arresto personale per debiti nell Italia liberale (Torino, 2004), pp.15-35.

${ }^{70}$ Leveille, Jules-Louis, De l abolition de la "contrainte par corps" (à propos de la loi projetée), en Revue Pratique de Droit Français, 22 (1866), pp. 305-332; Burg, Michel, Considérations sur la "contrainte par corps" en matière de dettes dites commerciales (Paris, 1820), pp. 10-22; LuCQ, Victor, Abolition de la “contrainte par corps” (Brusells, 1867), pp. 34; Zambrana Moral, Patricia, Histoire de six articles du Code civil francais: les droits du debiteur, honneur et contrainte par corps en Revue Historique de Droit Français et Étranger, 82 (2004) 4, pp. 589-611.

${ }^{71}$ Demars-Sion,Veronique, Contribution à $\mathrm{l}$ histoire de la faillite: étude sur la cession de biens à la fin de l Ancien Régime, en Revue Historique de Droit Français et Étranger, 75 (1997) 1, pp. 33-91; BAYle-MouIllaRd, Jean-Baptiste, De l'Emprisonnement pour dettes: considération sur son origine, ses rapports avec la morale publique et les intérêts du commerce, des familles, de la société; suivies de la Statistique de la "contrainte par corps" (Paris, 1836), pp. 258; Deymes, Louis, L'evolution de la nature juridique de la "contrainte par corps" (Toulouse, Diss. Univ. Toulouse, 1942), pp. 15-24, 33-40, 100125 . 
efectuaba un depósito en calidad de garantía (normalmente proporcionada por terceros, por lo general amigos o miembros de la familia $)^{72}$.

\section{La quiebra y los procedimientos de insolvencia en las ciudades alemanas.}

El empleo sancionatorio y coercitivo de la prisión del deudor insolvente se mantuvieron en varias ciudades alemanas durante la Edad Media, especialmente con la construcción de prisiones especiales para estos casos. El castigo corporal, el encarcelamiento y el fuerte estigma social continuaron en algunas ciudades alemanas durante los siglos XVIII y XIX, en otras veremos cómo ello cambió $^{73}$. No obstante, el paulatino crecimiento económico, y los cambios en el mercado del crédito fueron factores que llevaron gradualmente a procedimientos más sofisticados para la aplicación y el tratamiento de la insolvencia. El objetivo final era, en definitiva, maximizar la tasa de recupero en favor, e igualitariamente, para los acreedores. Ello no era sino consecuencia de que los acreedores en igualdad de trato asumían a pro rata pérdidas y ganancias ${ }^{74}$. Antes del siglo XVI, los procedimientos de regulación de la insolvencia no distaban a los descritos para el norte de Italia, sí tenían mayor flexibilidad y menos sanciones que permitían el abuso por parte de los deudores ${ }^{75}$. Especialmente ello se daba en el uso fraudulento -cuando no en connivencia con algún acreedor- de la transferencia voluntaria de bienes por el deudor ${ }^{76}$. Recuérdese que con ello se garantiza al menos ser liberado de la prisión por deudas. Este actuar y abuso fraudulento del proceso no pasó desapercibido para el legislador que reaccionó con la introducción de penas más severas.

La reforma de las leyes de quiebra se inició en Alemania medieval con el Reichstag de Lindau (1496-1497), siguiendo el Reichstag en Freiburg (1497-1498) que adoptó una reforma global. En 1500 se decretó la necesidad de implementar una reforma en Augsburgo. La propuesta fue, finalmente, implementada en 1532 después de muchas revisiones. Más de 30 años pasaron antes de que la nueva ley, que contenía entre otras una regulación de la insolvencia, con el nombre Constitutio criminalis Carolina entrara en vigor. El marco regulatorio de la insolvencia en una ley eminentemente penal marca

${ }^{72}$ Tomás y Valiente, Francisco, La prisión por deudas en los Derechos castellano y aragonés, en Anuario de Historia del Derecho Español, 30 (1960), pp. 249-489.

${ }^{73}$ Von HoInIngen, Hans, Beiträge zur geschichtlichen Entwicklung des strafbaren Bankerutts in Deutschland (Bonn, 1878), pp. 12-23

${ }^{74} \mathrm{BuCH}$, Georg, Zur Zession im deutschen mittelalterlichen Recht, en Zeitschrift der Savigny-Stiftung, germ. Abt., 34 (1913), pp. 429-433.

${ }^{75}$ TAEUBer, cit. (n. 58), pp. 40-56.

${ }^{76}$ Ambas, la "Lex Alamannorum" y el Derecho longobardo tenían prohibido vender a un hombre libre como esclavo u ordenar su muerte; al respecto, véase: SPANN, cit. (n. 11), pp. 72-73. 
el inicio de una nueva era: conceptos jurídicos vinculados a ideas tomadas de la doctrina penal y del derecho concursal italiano.

La Constitutio Carolina fue un punto de inflexión en el desarrollo del derecho penal alemán. Se incorporó en el ordenamiento jurídico con ello las ideas y visiones del derecho penal económico italiano. El gran avance fue la detallada tipificación de las conductas delictuales, el paso desde las descripciones generales a los delitos claramente definidos. Se efectúa la distinción entre el dolo y la culpa ${ }^{77}$. La intención del legislador era que el delincuente sólo debía ser castigado si su culpabilidad era probada. La prisión sigue siendo la pena por excelencia, pero el gran paso que dará esta ley es distinguir entre un deudor insolvente y un delincuente ${ }^{78}$. El deudor insolvente prestaba sus servicios al acreedor quien, a su vez, era responsable por su mantención y la de su familia. Ello no implicaba salario ni remuneración, ya que justamente el deudor pagaba sus deudas con los servicios que prestaba ${ }^{79}$. Éste podía solicitar su liberación si proporcionaba suficiente garantía para el acreedor, quien podía decidir discrecionalmente. La posibilidad de negar la libertad podía fundarse justamente en indicios que hagan pensar en el peligro de fuga del deudor, sin embargo, los acreedores se mostraban en general satisfechos y concedían la libertad en los siguientes casos: $i$ ) si en un plazo determinado directamente a través del trabajo del deudor, o por terceros (amigos de la familia o del deudor) se cancelaba la deuda; ii) si el deudor o un tercero ofrecían suficiente garantía y certeza de no ausentarse del territorio; iii) finalmente, en el caso de transferencia de los bienes del deudor a los acreedores. El rol principal que fue desempeñando la prisión al no ser un delito penal, fue el de medida asegurativa, o bien, de coerción. Además los costos de la servidumbre personal para el acreedor (especie de prisión privada) hizo que fuera dejándose de lado para ser sustituida por la prisión bajo la autoridad pública, aunque los lugares eran de deficiente calidad y con gran hacinamiento. No pocos veían con buenos ojos la responsabilidad personal cumplida en forma de servidumbre personal (o prisión privada), no obstante los costos de manutención mínimos que debía asumir el acreedor para con el deudor y su familia, dada la precaria -y hasta inhumana- situación de las cárceles públicas ${ }^{80}$.

La prisión de los deudores era a la vez una herramienta eficaz de aplicación

${ }^{77}$ BRESSLER, cit. (n. 28), pp. 111-120.

${ }^{78}$ MeIER, Anke, Die Geschichte des deutschen Konkursrechts, insbesondere die Entstehung Reichskonkursordnung von 1877 (Frankfurt, 2003), pp. 60-72.

${ }^{79}$ Vollmershausen, Christiane, Vom Konkursprozess zum Marktbereinigungsverfahren (Münter, Diss. Ausburg, 2007), pp. 28-30.

${ }^{80}$ Dabelow, Christoph, Ausfübrliche Entwicklung der Lebre vom Concurse der Gläubiger (Halle, 1801), pp. 30-53. 
de la ley, así como una alternativa eficaz a las formas violentas de autoayuda. La prisión pública de alguna forma no dejaba de significar el monopolio de la fuerza pública en la aplicación de la ley. La insolvencia, salvo que existiera fraude, dejó de ser considerada una conducta criminal y quedó reservada para el ámbito de la responsabilidad civil patrimonial ${ }^{81}$. El insolvente privado de libertad no estaba sujeto a una sanción penal, sino a una medida cautelar o de coerción. Ya a finales del siglo XV, comienzos del XVI se reguló la liberación de responsabilidad del deudor que voluntariamente transfería sus bienes a los acreedores ${ }^{82}$. No quedaba pues sujeto a responsabilidad por deuda insoluta ya que parte del acuerdo de transferencia era justamente la reducción del monto original en capital e intereses.

Cabe señalar que la servidumbre por deudas (prisión privada) y las la torres de detención de deudores (prisión pública) fueron las dos formas más extremas de ejecución personal en la Alemania medieval y moderna ${ }^{83}$. A lo que cabe agregar que su uso no era punitivo, ya que la sola insolvencia dejó de ser delito para pasar al ámbito de la responsabilidad civil. Incluso se afirma que el término "servidumbre por deudas" no tiene ninguna base en las fuentes germanas y que resulta de un error de interpretación del siglo XIX sobre el uso de estas medidas asegurativas y/o de coerción. Mas era asimilable a la "encomienda" usada en las colonias españolas. El deudor no tenía una obligación laboral para con el acreedor ${ }^{84}$. La detención no era un castigo real, sino solo un medio eficaz de ejecución contra los deudores insolventes: un medio de coerción para obtener el pago de la deuda o una garantía por el deudor, o bien, por un tercero. Tratándose de deudores que además eran comerciantes las deudas eran mucho mayores, a lo que se sumaba el riesgo para el normal tráfico mercantil que significaba ese deudor ${ }^{85}$.

\section{LA INSOLVENCIA DE PERSONAS NATURALES Y LA AFECTACIÓN DE INGRESOS PARA PAGO DE CRÉDITOS (LA “SERVIDUMBRE” POR DEUDAS RESIDUALES DEL SIGLO XXI)}

1. La insolvencia en el caso de las pesonas naturales (normalmente consumidores) difícilmente pueda (en contra de los intereses del deudor y también de los acreedores) contentarse con mecanismos de liquidación de

${ }^{81}$ BRESSLER, cit. (n. 28), pp. 131-138.

${ }^{82}$ Vollmershausen, cit (n. 79), pp. 27-34.

${ }^{83}$ DABELOW, cit. (n. 80), pp. 30 ss.; para una comparación entre el proceso de arresto en Alemania y en Italia, véanse: KIsCH, Guido, Der deutsche Arrestprozess (Wien, 1914), pp. 15; W ACH, Adolf, Der italienische Arrestprocess (Leipzig, 1868), pp. 80.

${ }^{84}$ BRESSLER, cit. (n. 28), pp. 210-220.

${ }^{85}$ Ibíd., pp. 203-220. 
un patrimonio normalmente escaso para satisfacer a todos los acreedores. Ese estado de sobreendeudamiento o insolvencia no se corresponde normalmente con un estado o situación querida y preordenada por el deudor. Entra, claro está, dentro un manejo no adecuado de las finanzas, pero el resultado de imposibilidad de cumplir suele no ser voluntario. Por ello es necesario un sistema de tratamiento de la insolvencia inclusivo de las personas naturales y diferenciado de la empresa como deudor en un proceso concursal.

El deudor se encuentra en dificultades financieras si sus activos totales son inferiores a sus pasivos totales, o si no es capaz de pagar la deuda por otros motivos, cuando se debe: no cuenta con libros de comercio, balances u otros métodos contables sistemáticos, como normalmente sí disponen las empresas. En el Derecho concursal contemporáneo el fenómeno tiene contemplación legislativa de diversas formas pero dejó de limitarse solo a la empresa (otrora solo al comerciante). Ello preocupa al Estado en tanto el costo social de deudores (personas naturales) sobreendeudades y sin alternativas de tratamiento diferenciado, como el existente para una empresa en la misma situación ${ }^{86}$. Individualmente, comparado un caso de insolvencia personal con uno empresarial, podría no tener mayor significancia económica, pero la comparación correcta debiera hacerse en base a la cantidad y condiciones de los afectados por la insolvencia personal, lo que ya sería significativamente complejo por las consecuencias sociales, económicas y familiares en forma directa. Igualmente aún sin mayor visión sistémica del problema, no era ni es infrecuente que un acreedor pueda satisfacerse totalmente a costa de dejar sin su parte a los restantes si el fenómeno no tenía siquiera contemplación normativa. No obstante esos grados cercanos o lejanos a un estado de insolvencia real han tenido un gran desenvolvimiento recién en los últimos 10 años, directamente relacionados con los llamados "estados o fases preconcursales" de reorganización y saneamiento. En algunos casos ello reducido a las empresas, en otros con las debidas adecuaciones, aplicables también a las personas naturales. Especialmente los términos "sobreendeudamiento" e "insolvencia" podrían tener el mismo alcance personal a los efectos de permitir una renegociación o reestructuración de la deuda (o saneamiento) sin importar si el deudor sea o no persona natural y considerando que se trata de procedimientos dónde el legitimado activo es justamente éste que se encuentra en crisis financiera: $i$ ) en el caso del derecho alemán el sobreendeudamiento solo es aplicable y pensable para la empresa (con la finalidad de regulación del salvataje o reorganización) no así para el consumidor; ii)

${ }^{86}$ JACKsON, Thomas, The Logic and Limits of Bankrupcy Law (Washington, 2001), pp. 12-17. 
otros casos lo aplican indistintamente a la empresa y personas naturales (como parece ser el modelo francés e italiano).

2. Tal cual se pudo ver, el desarrollo histórico del Derecho concursal pasó por etapas donde no distinguió entre insolvencia personal o empresarial y tuvo en mira la igualdad entre los acreedores para la distribución y prorrateo de pérdidas y ganancias. El rol del consenso entre los acreedores y el deudor con la intervención de un tercero parece ser también la salida para la insolvencia o sobreendeudamiento de personas naturales ${ }^{87}$. Por la Ley de reforma concursal alemana del 2001 se pudo lograr una mejor y más amplia sistematización del acceso al proceso concursal. Desde su inicio se tuvo en cuenta la necesidad de evitar una consecuencia probable -aunque real-de presión sobre las finanzas públicas: por un lado un equilibrio tutelando el crédito, pero considerando la insolvencia del deudor (actual o inevitable) para evitar un empobrecimiento masivo en un sector vulnerable como es el de los consumidores ${ }^{88}$.

Los sistemas comparados vigentes y propuestos son disímiles: desde la renegociación con los acreedores bajo el control de un tercero con condonación parcial de deudas hasta el modelo "fiduciario", en el cual se asocia la buena conducta del deudor como un administrador que resguarda los intereses de acreedores y del deudor. El deudor tiene limitación a su facultad de disposición y administración, de modo que un porcentaje de sus ingresos son destinados para el pago a sus deudas durante un período de tiempo, solo percibiendo lo mínimo para su sustentación y la de su entorno familiar. Transcurrido cierto plazo puede solicitar su liberación total ${ }^{89}$.

3. La armonización y, en algunos casos, la unificación europea en materia de insolvencia no ha estado exenta de problemas en la oferta de las mejores alternativas de foro para el tratamiento del deudor como persona natural insolvente ${ }^{90}$. La jurisprudencia ha sido favorable pro debitore cuando éste recibe

\footnotetext{
${ }^{87}$ Ya afirmado por KoHLER, cit. (n. 1), pp. 8-11.

${ }^{88}$ Harder, Sebastian,Die geplante Reform des Verbraucherinsolvenzrechts, en Neue Zeitschrift für das Recht der Insolvenz und Sanierung (2012), pp. 113.

${ }^{89}$ Kilborn, Jason, The Innovative German Approach to Consumer Debt Relief: Revolutionary Changes in German Law, and Surprising Lessons for the United States, en Nw.J. Int'l L. \& Bus., 24 (2003-2004), pp. 257.

${ }^{90}$ Para una investigación completa y actual sobre el Derecho de la insolvencia de las personas naturales en Europa, véase el trabajo del Instituto Max Plank de Luxemburgo en conjunto con la Universidad de Heidelber y Viena, The External Evaluation of Reg. No 1346/2000/EC on Insolvency Proceedings (Heidelberg - Luxemburgo - Viena, 2013), pp. 66 ss. [disponible en: http://www.mpi.lu/uploads/media/evaluation_insolvency_en.pdf].
} 
mejor tratamiento (menor plazo de buena conducta cumplidora) como son las normas en la materia en la Insolvency Act de Inglaterra o la fragmentada, pero benévola, legislación en Francia. Ello convierte a determinados foros en especialmente atractivos para los deudores extranjeros, ya que reciben un tratamiento más beneficioso y a sus intereses. ${ }^{91} \mathrm{Al}$ igual que en otras áreas, se ha convertido en una verdadera competencia de "forum-shopping" de la insolvencia, entre los ordenamientos jurídicos nacionales de los Estados miembros de la Unión Europea ${ }^{92}$. El deudor tiene la oportunidad de elegir el Estado en el cual puede ser tratado menos duramente y que quede liberado de sus deudas lo más rápido posible para volver a tener un estatus financiero de solvente. Esta posibilidad de elección estratégica del deudor como persona natural (futuro insolvente) no ha estado exento de abusos acudiéndose más que frecuentemente al llamado "turismo para contraer deudas" teniendo en mente el futuro trato en caso de insolvencia ${ }^{93}$. Tal cual se trató en la introducción de este estudio, la ley alemana antes de la reforma del 2012 contemplaba un período de pago y buena conducta para liberar de seis años (luego reducido a tres), pero que contrasta fuertemente con el sistema inglés donde el plazo de liberación asciende a doce meses.

También en Francia existen una serie de procedimientos eficientes y con menor carga temporal. Ello contrasta, en su origen, con la tradición concursal francesa donde el sujeto legitimado para intervenir como fallido debía ser un

${ }^{91}$ Hay decisiones de los tribunales ingleses que evidencian la voluntad de los deudores justamente de eludir el pago de sus obligaciones contraídas en un estado miembro sometiéndose al derecho concursal más benigno de otro estado: el llamado "turismo quiebra”. Son notables las alternativas ofrecidas por los abogados tanto de acreedores como de deudores en Inglaterra para retener la competencia. En Alemania por su lado se pronunciaron algunos fallos que ven aquella situación como abusiva y solo preordenada para obtener la exención de la deuda residual por Derecho extranjero afectándose el orden público alemán (por ejemplo LG Köln, sentencia del 14 de octubre de 2011, Az. 82 O 15/08). Contraria parece ser la visión jurisprudencial del Tribunal de Justicia Europeo sobre el reconocimiento de procedimientos extranjeros de insolvencia en la Unión Europea, admitiendo tales prácticas; así por ejemplo EuGH BB 2010, 529 - MG Probud, con una nota de Fichtner).

${ }^{92}$ WeLLER, Marc-Phillippe, Forum Shopping im Internationalen Insolvenzrecht? en IPRax (2004), pp. 412 (413); cfr. Wessels, Bob, EU Insolvency Regulation: Where to go From Here? en International Insolvency Law Review, 3 (2011), pp. 298-308. Pero el Tribunal (Landgericht) de Trier, en la sentencia 5 O247/12 del 02 de Mayo de 2013 aclaró que Inglaterra concedió la liberación de la deuda residual en Alemania y en particular, reconoció el "Forum Shopping", es decir, consideró que no se violentaba el orden público aleman. En el mismo sentido véanse los fallos de OLG Köln ZIP 2013, 644, n. 73; Brandenburgisches OLG ZlnsO 2011, 1563; OLG Nürnberg NJW 2012, 862.

${ }^{93}$ Knof, Béla, Europäisches Insolvenzrecht und Schuldbefreiungs- Tourismus, en $Z \operatorname{lns} O$ (2005), pp. 1017-1025. 
comerciante ${ }^{94}$. Son justamente las regiones que tuvieron influencia fuerte de Alemania (en su momento anexadas, luego recuperadas para Francia) donde se originaron y subsistieron en el tiempo, procesos concursales incluyentes de las personas naturales y con plazos menores: así las regiones fronterizas del Rin Alto (Estrasburgo), Rin Bajo (Mulhouse) y Moselle (Metz) que perteneció hasta 1918 al Imperio alemán.

En la historia de la insolvencia en Francia desde 1789, la visión sobre la libertad -solo predicable como atributo de la persona natural- habría contribuido a excluirla como sujeto concursal ya que siempre supone una elección que opta entre cumplir o no con sus obligaciones. La voluntad libre (artículo 1134 CCFr.) y la "liberté contractuelle" serían inviolables. Por lo tanto, la ecuación fue: capacidad de pago/cesación de pago = demora en el pago = pagos $/$ "default" = incumplimiento (que implicaba imputación y exclusión de buena fe), sin ningún tamizador como la "incapacidad de pago" (ya aplicable en la forma de "cesación de pago" para la empresa como sujeto concursal), aunque impensable para persona natural. La vigencia del derecho alemán se mantuvo parcialmente luego de anexados los territorios a Francia, así se combinó el derecho local con el francés: se mantuvo la ley concursal alemana de 1877 , lo que explica la existencia de un procedimiento de insolvencia para los consumidores como ley local dentro del contexto general del derecho francés ${ }^{95}$. Así no solo una empresa y comerciante eran sujetos legitimados como partes insolventes, sino que también la persona natural, el consumidor, por su deuda residual impaga. Las disposiciones de la Ley de insolvencia francesa ${ }^{96}$ (actualmente artículo 620-1 CCom.) se aplican de conformidad con el artículo 670-1 de ese cuerpo normativo también a las personas naturales. El proceso personal de rétablissement ${ }^{97}$ corresponde a la insolvencia personal (quiebra o insolvencia civil ("faillité civile"), según otra terminología) inicialmente a los departamentos fronterizos Bas-Rhin, Haut-Rhin y Moselle. A partir de 2003 se extiende el procedimiento para ser

${ }^{94}$ D'Avorne, Marc, Internationale Zuständigkeit des deutschen Insolvenzgerichts bei offenkundiger "Rückkehroption" des ehemals selbständig wirtschaftlich tätigen Schuldners mit dem Ziel der Restschuldbefreiung, en Neue Zeitschrift für Insolvenzrecht, 8 (2011), pp. 310 ss.

${ }^{95}$ Lemanissier, Jean, Faillité civile en Alsace et en Lorraine (Caen, 1939), pp. 12 34; Lencou, Dominique, La faillité personnelle et la banqueroute (Grenoble, Diss. Université de Bordeaux I, 1980), pp. 45-69.

${ }^{96}$ Trancou, Georges, De lextension de la faillite aux non-commerçants (Paris, Diss. Université de Paris, 1918), pp. 20-43; Budin, Jean, La faillité civile (Paris, 1935), pp. 10-25.

${ }^{97}$ KILborn, Jason, La responsabilisation de l'Economie: What the United States Can Learn From the New French Law on Consumer Overindebtedness, en Michigan Journal for International Law, 26 (2005), pp. 619 ss. 
aplicado a toda Francia. El deudor debe haber agotado todas las posibilidades de solución extrajudicial de deudas y el juez del concurso decide en última instancia aprobar o no el procedimiento y planes en caso de insolvencia. ${ }^{98}$

Italia introdujo en el 2012 la figura del "sobredebitamento" que permite un tratamiento procesal de la insolvencia de quienes no pueden ser sujetos de "fallimento". En la misma idea que lo que se viene desarrollando permite a la persona natural (aun cuando no se haya empleado el término "consumidor") acceder a un nuevo inicio 99 . Ya se había comenzado a hacer referencia a la crisis económica familiar como materia necesitada de una adecuada regulación y que no era suficientemente regulada por el proceso de insolvencia ${ }^{100}$.

4. En la evaluación del riesgo crediticio (actual o eventual) juega un rol preponderante la información sobre el patrimonio y relaciones del deudor. Han sido y son el fraude, el engaño y la información insuficiente y/o ocultamiento de ella lo que motivó que muchas culturas hayan adoptado medidas drásticas con el objetivo de una adecuada protección del crédito a partir de

${ }^{98}$ Véase en detalle el trasfondo histórico desde la Revolución Francesa hasta los cambios posteriores en QUENILLET, Martine, La bonne foi du débiteur surendetté: une voie sans issie, en $L P A ., 5$ (1992), pp. 17. El régimen de la insolvencia considerando ya a la persona natural como sujeto concursal resurge lentamente en el siglo XX, en efecto que aquella pueda afectar a cualquier tipo de personas era lo común desde Roma hasta la Edad Moderna. Principalmente por la crisis económica de 1980 desencadenaron el inicio de los cambios y adaptaciones legales. Desde entonces las leyes de 1989, 1995 y 1998 hasta las reformas de 2003, 2010 y 2011 vigentes, han buscado regular distintos metodos para controlar el sobreendeudamiento de las personas naturales. La ley de los consumidores (art. L. 330-1) determina el método para la bancarrota del consumidor. Paralelamente rigen las disposiciones especiales para Haut-Rhin, BasRhin y Moselle (art. L. 670-1 ss. Código de Comercio), que rige desde 2003 en todo Francia. Para más detalles, véase: VIGNEAU, Vincent - Bourin, Guillaume-Xavier - CyrIL, Cardini, Droit du surendettement des particuliers (Paris, 2012), pp. 1-24, 36-41.

${ }^{99}$ Guiotтo, Alberto, La nuova procedura per l'insolvenza del soggetto non fallibile: osservazioni "in itinere", in Fall. (2012), pp. 21-32; MARCUCCI, Monica, Insolvenza del debitore civile e "fresh start". Le ragioni di una regolamentazione, en Anal. giur. ec. (2004), pp. 221-241.

${ }^{100}$ Según Brogi, Riccardo, Bilancio e indebitamento delle famiglie italiane, en Anal. giur. ec. (2004), pp. 265-281: "Infatti, consegue che una famiglia risulta sovraindebitata allorché debba ridurre le proprie spese ad un livello inferiore a quello che i membri si attendevano di praticare. Da ció, la stessa dottrina economica italiana ha iniziato a promuovere studi sull indebitamento familiare, pervenendo a definire il sovraindebitamento secondo il modello del ciclo vitale e del reddito: il livello del consumo è fissato in base alle risorse attese nell intero orizzonte di vita, andando cioè oltre l' effettivo momento in cui le risorse stesse sono attese nella loro disponibilità". En el mismo sentido: CASTAGNOLA, Angelo, L'insolvenza del debitore civile nella re-sponsabilità patrimoniale, en Anal. giur. ec. (2004), pp. 243-263. 
incentivos para evitar aquellos actos y premiar la cooperación del deudor ${ }^{101}$. Pero tampoco se puede dejar de mencionar que allí donde nunca existió la posibilidad de un proceso concursal para personas naturales, especialmente consumidores, se creaba un círculo vicioso con retraso en los pagos, acumulación de deudas vencidas y exigibles, concurrencia de acreedores y finalmente un complejo estado de insolvencia ${ }^{102}$. Un estado ajeno a la voluntad del deudor y en el que el castigo físico, de confinamiento y de infamia eran la consecuencia natural para algo imputable al deudor equiparable al hurto, algo directamente relacionado con su voluntad de ser deudor. Las personas que habían caído en la deuda y no podían tomar otro préstamo, eran puestas bajo custodia y al servicio del acreedor para su pago. La estadía en la cárcel pública, como alternativa, no estaba limitada en el tiempo y podía emplearse como medida de coerción hasta el pago de la deuda por el deudor o sus cercanos. Sin embargo se deben diferenciar modalidades de cómo era tratado el deudor insolvente. No solo en el Derecho romano antiguo, sino en el germano e italiano medieval y hasta inicios de la Edad Moderna, el deudor insolvente recibe tratamiento penal, incurre en un delito y se aplican las sanciones desde esa óptica ${ }^{103}$.

5. Esta primera fase es, a menudo, seguida de un período en el que el legislador tuvo que mitigar las reglas de trato crueles por razones humanitarias y por el surgimiento de un mercado financiero que abría las expectativas para los interesados. La esclavitud y la servidumbre por deudas fueron reemplazadas con el tiempo por modalidades menos fuertes, como el trabajo forzado a favor del acreedor quien debía brindar lo mínimo para la subsistencia del deudor y su familia, o bien, el uso de la prisión pública que reemplazaba a las prisiones privadas (menor costo para el acreedor a peores condiciones de hacinamiento para el deudor) ${ }^{104}$. Ello se combinaba o no con la posibilidad voluntaria para el deudor de traspasar su patrimonio en favor del acreedor o poner a disposición garantías propias o de terceros. Por último, la visión y concepción de delito quedó reducida a los casos de deudores fraudulentos. Contemporaneamente no hay infamia y se eliminaron muchos de los mecanismos de ejecución física, pero un sistema sin regulación de la insolvencia

${ }^{101}$ Cfr. Mann, Bruce, Republic of Debtors: Bankruptcy in the Age of American Independence (Cambridge, 2002), pp. 10-25.

${ }^{102}$ Efrat, Rafael, The Evolution of Bankruptcy Stigma, en Theoretical Inquiries in Law, 7 (2006), pp. 364-393.

${ }^{103}$ El informe del Banco Mundial sobre el complicado estado de deudas de las personas naturales se dio a conocer en 2012. Disponible en: http://siteresources.worldbank. org/INTGILD/Resources/WBPersonalInsolvency ReportOct2012DRAFT.pdf;

${ }^{104}$ JACOBI , cit. (n. 13), pp. 123; cfr. FRADE, cit. (n. 11), pp. 45-50; 
de personas naturales o consumidores de hecho deviene en un modelo donde la mácula socio-económica que implica ese deudor, le cierra el acceso a muchos bienes e incluso a la posibilidad de generarlos a partir de su propio trabajo: un juego de suma cero desde el punto de vista de los acreedores y el deudor. Esto especialmente se agudiza en períodos de crisis económica y que normalmente instan a cambios.

Hoy, casi todos los ordenamientos jurídicos cuentan con modos de afrontar la insolvencia de personas naturales. Especialmente exitosos son aquellos que permiten una segunda oportunidad, a partir de la buena conducta y voluntad de cooperación en relación a la deuda insoluta. Así como la esclavitud cedió en favor de una servidumbre personal (prisión en los aposentos del acreedor), ésta a su vez fue abriéndose a un trabajo o relación laboral del deudor para con su/s acreedore/s que debían garantizarle un sustento mínimo para sí y su familia ${ }^{105}$. El paso al derecho concursal contemporáneo es que el deudor continúe trabajando y generando ingresos, de los cuales sus acreedores reciben obligatoriamente su cuota durante un período de tiempo, siempre respetando un mínimo para la subsistencia y necesidades básicas de aquel y su familia ${ }^{106}$. El pago será parcelado y modalizado en el tiempo en base a los ingresos totales del deudor hasta llegar a un remanente que será condonado y permite un nuevo inicio para el deudor. Las similitudes en las alternativas se repiten y perfeccionan desde Roma, pasando por las Edades Medias y Modernas. Lo cierto que lo ofrecido y deseable como derecho concursal de las personas naturales o consumidores en la economía y tráfico contemporáneo no es original, tampoco ajena a propuestas ya históricas en el tiempo y por lo visto paralelas y siempre vigentes de diversas formas ${ }^{107}$.

\section{ConCLusión}

El desarrollo del proceso concursal para dar cauce a la insolvencia y resguardar los múltiples intereses en juego fue un largo proceso histórico, largo de varios siglos. La insolvencia se equiparó a una conducta sancionable civil y penalmente. Ello permitía que el acreedor, además de los bienes del deudor, también podía obtener el cumplimiento de su deuda en la persona del deudor por medio de su detención (sea vista como pena o medida de coerción) y trabajo forzosos. La servidumbre y prisión del deudor significaron castigos estigmatizantes que tenían por efecto la exclusión del acceso a bienes

${ }^{105}$ KILBORN, Jason, Expert Recommendations and the Evolution of European Best Practices For the Treatment of Overindebtedness, 1984-2010 (Deventer, 2011), pp. 6370.

${ }^{106}$ PAPE, cit. (n. 13), pp. 150.

${ }^{107}$ LAROCHE, cit. (n. 23), pp. 558-559. 
y servicios, lo que se extendió desde la Edad Media hasta la Contemporánea. La distinción entre comerciantes y no comerciantes tuvo relevancia en aspectos del proceso concursal en las pujantes ciudades italianas del norte en la Edad Media y Moderna. La calidad de persona natural del deudor no era un obstáculo para considerarlo sujeto pasivo de un proceso concursal fundado en su insolvencia o sobreendeudamiento. El tratamiento del deudor insolvente experimentó un desarrollo similar tanto en el Derecho romano con procedimientos variados y sucesivos en el tiempo como en la Edad Media y Moderna: el paso desde la insolvencia subjetivamente imputable y tipo delictual, como de segregación social hacia el estado de incapacidad de pago, en muchos casos ajeno a la voluntad del deudor de buena fe, fue lento. Incluso con la despenalización en las leyes alemanas, el insolvente conservaba ciertos efectos de la histórica infamia que lo terminaban limitando social y económicamente.

En una economía en crecimiento cada vez más compleja, basado cada vez más en el crédito, había una creciente necesidad de acceso a la información de crédito, y los instrumentos de disciplina y control. El Estado se retiró de estas tareas, las que fueron asumidas por los mercados. Asociaciones de empresarios establecieron organizaciones que proporcionan información de crédito recogidos, estandarizada y centralizada. Tanto las actividades gubernamentales (con asesores de insolvencia, profesionales de la insolvencia privados y organismos públicos) y el acuerdo entre los acreedores y los deudores son formas de dar una cabida procesal a la persona natural/ consumidor insolvente (un sucedáneo menos fuerte y evidente de la prisión o mejor calificable de la servidumbre por deudas): la insolvencia individual o de liberación de deuda residual ${ }^{108}$.

Con los métodos de alivio de deudas residuales disponibles en Alemania y reformados en 2013, los deudores tienen la oportunidad de ser liberados de sus obligaciones después de tres años en lugar de seis de sus deudas restantes. Las condiciones son: el pago de las costas judiciales y al menos una cuarta parte de las reclamaciones dentro de este período. En el futuro, esta oportunidad estará abierta a todas las personas físicas: ya no se limita a grupos específicos de personas, como los consumidores o empresarios. Al mismo tiempo, las medidas para fortalecer los derechos de los acreedores se proporcionan. Se lleva a cabo de acuerdo a la tendencia en la mayoría de países europeos, para acortar los plazos de amortización como parte de un proceso

${ }^{108}$ Spooner, Joseph, Fresh Start or Stalemate? European Consumer Insolvency Law Reform and the Politics of Household Debt en European Review of Private Law, 21 (2013), pp. 747-794; SсHмеRвACH, Ulrich, Vereinfachung des Restschuldbefreiungsverfahrens, en $\operatorname{Zins} O$ (2012), pp. 916. 
de quiebra personal de unos cinco años a tres años ${ }^{109}$. Otras reformas en la ley de bancarrota personal aún no se han implementado: la reducción en la duración del procedimiento conlleva a una celeridad en la liberación de la deuda residual. Claro está que es un ámbito regulatorio donde las deudas condonadas terminan siendo absorbido por la masa de acreedores, pero al mismo tiempo se impide un agravamiento en la situación financiera de masas de consumidores de bajos ingresos y en riesgo de pobreza ${ }^{110}$.

A la solución y el tratamiento del sobreendeudamiento y de los hogares insolventes de los consumidores de hoy en día, los procedimientos de insolvencia distintos de la quiebra personal, o de la deuda residual son una contribución importante ${ }^{111}$. Nada nuevo bajo el sol: desde las normas de Roma y la Edad Media, siempre se puede aprender. Lo que se presenta como un nuevo reto es proponer una medida al endeudamiento excesivo. Esto debe ser contrarrestado con medidas complementarias tales como los requisitos de información y servicios de consultoría ${ }^{112}$. Ambas perspectivas (ex post $\mathrm{y} e x$ ante) a largo plazo pueden ayudar a mantener la responsabilidad del individuo por sus acciones y los intereses de los acreedores.

\section{BIBLIOGRAFÍA}

BAYER, Hieronymus, Theorie des Concurs-Processes nach gemeinem Rechte ( $4^{\mathrm{a}}$ edición y $2^{\mathrm{a}}$ impresión, München, 1868), IV.

BAyle-Mouillard, Jean-Baptiste, De l'Emprisonnement pour dettes: considération sur son origine, ses rapports avec la morale publique et les intérêts du commerce, des familles, de la société; suivies de la Statistique de la "contrainte par corps"(Paris, 1836). BeHRENDs, Okko, Der Zwölftafelprozeß: zur Geschichte des römischen Obligationenrechts (Göttingen, 1974).

Bethmann-Hollweg, August von, Der römische Civilprozess (Bonn, 1865)-

Bonini, Roberto, "La carcere dei debitori": linee di una vicenda settecentesca (Torino, 1991).

${ }^{109}$ Hofmeister, Carsten - Schulz, Eckehard, Stärkung der außergerichtlichen Einigung: wirklich gut oder gut gemeint? en Zeitschrift für Verbraucher-und PrivatInsolvenzrecht, 6 (2012), pp. 134.

${ }^{110}$ Dudoso JÄGER, Ulrich, Schnellere Restschuldbefreiung durch Mindestquote: $\mathfrak{S}$ 300 Abs. 1 Satz 2 Nr. 1 InsO-RefE 2012 auf dem Prüfstand, en ZVI. (2012), pp. 142.

${ }^{111}$ SCHÖNEN, Simone, Verbraucherinsolvenzrecht im internationalen Vergleich unter besonderer Berücksichtigung der Vorschriften zur Restschuldbefreiung (Teil II), en ZVI. (2010), pp. 81.

${ }^{112}$ Kilborn, Jason, Two Decades, Three Key Questions, and Evolving Answers in European Consumer Insolvency Law: Responsibility, Discretion, and Sacrifice, en NiEmI, Johanna - Ramsay, Iain - Whitford, William (editores), Consumer Credit, Debt and Bankruptcy: Comparative and International Perspectives (Oxford, 2009), pp. 307. 
Bressler, Steffen, Schuldknechtschaft und Schuldturm. Zur Personalexekution im sächsischen Recht des 13.-16. Jahrhunderts, (Berlin, 2004).

Brogi, Riccardo, Bilancio e indebitamento delle famiglie italiane, en Anal. giur. ec. (2004).

BuCH, Georg, Zur Zession im deutschen mittelalterlichen Recht, en Zeitschrift der SavignyStiftung, germ. Abt., 34 (1913).

Budin, Jean, La faillité civile (Paris, 1935).

Burg, Michel, Considérations sur la "contrainte par corps" en matière de dettes dites commerciales (Paris, 1820).

Carrelli, Edoardo, Ancora sull'origine della "bonorum venditio", en Studia et Documenta Historiae et Iuris, 10 (1944) 2.

CASSANDro, Giovanni, Le rappresaglie e il fallimento a Venezia nei secoli XIII e XIV con documenti inediti (Torino, 1938).

Castagnola, Angelo, L'insolvenza del debitore civile nella re-sponsabilità patrimoniale, en Anal. giur. ec. (2004).

CoHen, Jay, The History of Imprisonment for Debt and Its Relation to the Development of Discharge in Bankruptcy, en Journal of Legal History, 3 (1982).

D'Amati, Laura, “Curator bonorum”: una rilettura, en Bullettino dell'Istituto di Diritto Romano "Vittorio Scialoja”, 33-34 (1991-1992).

D'Avoine, Marc, Internationale Zuständigkeit des deutschen Insolvenzgerichts bei offenkundiger "Rückkehroption" des ehemals selbständig wirtschaftlich tätigen Schuldners mit dem Ziel der Restschuldbefreiung, en Neue Zeitschrift für Insolvenzrecht, 8 (2011).

DABELOw, Christoph, Ausfübrliche Entwicklung der Lehrevom Concurse der Gläubiger (Halle, 1801), pp. 30-53.

Demars-Sion,Veronique, Contribution à l'histoire de la faillite: étude sur la cession de biens à la fin de l'Ancien Régime, en Revue Historique de Droit Français et Étranger, 75 (1997) 1.

Deymes, Louis, L'evolution de la nature juridique de la "contraintepar corps" (Toulouse, Diss. Univ. Toulouse, 1942).

Di Salvo, Settimio, La "lex Laetoria", minore età e crisi sociale fra il III e il II sec. a. C. (Napoli, 1979).

Ducos, Michèle, La crainte de l'infamie et l'obéissance à la loi. (Cic, De Rep., V. 4. 5), en Revue d'Études Latines, 57 (1979).

EFrat, Rafael, The Evolution of Bankruptcy Stigma, en Theoretical Inquiries in Law, 7 (2006).

Finley, Moses, La servitude pour dette, en Revue Historique de Droit Français et Étranger, $43(1965) 4$.

FORSTER, Wolfgang, Konkurs als Verfahren: Francisco Salgado de Somoza in der Geschichte des Insolvenzrechts (Köln - Weimar, 2009).

Frade, Catarina, Bankruptcy, Stigma and Rehabilitation en ERA Forum, 13 (2012).

FRIND, Frank, Praxis-Prüfstand:Die Vorschläge zur Neuordnung des Insolvenzverfahrens natürlicher Personen, en ZinsO. (2012).

Giuffrè, Vicenzo, La c. d. "lex Iulia de bonis cedendis", en Labeo, 18 (1972).

Giuffrè, Vicenzo, Sull'origine della "bonorum venditio" come esecuzione patrimoniale, en Labeo, 39 (1993).

Gloria, Andrea, La pietra del vituperio nel salone di Padova (Padua, 1851).

Gratzer, Karl, "Introduction” a Gratzer, Karl - Stiefel, Dieter (editores), History of Insolvency and 
Greenidge, Abel Hendy Jones, "Infamia". Its Place in Roman Public and Private Law (Oxford, 1894).

Guiotто, Alberto, La nuova procedura per l'insolvenza del soggetto non fallibile: osservazioni "in itinere", in Fall. (2012).

HARDER, Sebastian,Die geplante Reform des Verbraucherinsolvenzrechts, en Neue Zeitschrift für das Recht der Insolvenz und Sanierung (2012).

HIRTE, Heribert, Stellungnahme zum Regierungsentwurfeines Gesetzes zur Verkürzung des Restschuldbefreiungsverfahrens und zur Stärkung der Gläubigerrechte (BT-Drucks. 17/11268) für den Deutschen Bundestag, Sitzung des Rechtsausschusses am 14. Januar 2013, 1-8 [Disponible en: http://www.bundestag.de/bundestag/ausschuesse17/ a06/anhoerungen/archiv/36_Restschuldbefreiung/04_Stellungnahmen/Stellungnahme_Hirte.pdf].

Hofmeister, Carsten - SCHulz, Eckehard, Stärkung der außergerichtlichen Einigung: wirklich gut oder gut gemeint? en Zeitschrift für Verbraucher- und Privat-Insolvenzrecht, 6 (2012).

Ioannatou, Marina, Affaires d'argent dans la correspondance de Cicéron en L'aristocratie sénatoriale face à ses dettes (Paris, Diss. Université de Paris II, 2006), I-II.

Io annatou, Marina, Le code de l'honneur des paiements. Créanciers et débiteurs àla fin de la République romaine, en Annales. Histoire, Sciences Sociales, 6 (2001).

JACKson, Thomas, The Logic and Limits of Bankrupcy Law (Washington, 2001).

JАСОВI, Florian, Insolvenzrechtsreform zum Verfahren natürlicher Personen (Insbüro, 2012).

JäGER, Ulrich, Schnellere Restschuldbefreiung durch Mindestquote: $\$ 300$ Abs. 1 Satz 2 Nr. 1 InsO-RefE 2012 auf dem Prüfstand, en ZVI. (2012).

KaSER, Max, "Infamia" und "ignominia" in den römischen Rechtsquellen, en Zeitschrift der Savigny-Stiftung, 73 (1956).

KILBORN, Jason, Expert Recommendations and the Evolution of European Best Practices For the Treatment of Overindebtedness, 1984-2010 (Deventer, 2011).

Kilborn, Jason, La de l'Economie: What the United States Can Learn From the New French Law on Consumer Overindebtedness, en Michigan Journal for International Law, 26 (2005).

Kilborn, Jason, The Innovative German Approach to Consumer Debt Relief: Revolutionary Changes in German Law, and Surprising Lessons for the United States, en Nw. J. Int'l L. \& Bus., 24 (2003-2004).

KILborn, Jason, Two Decades, Three Key Questions, and Evolving Answers in European Consumer Insolvency Law: Responsibility, Discretion, and Sacrifice, en NiEmi, Johanna - Ramsay, Iain - Whitford, William (editores), Consumer Credit, Debt and Bankruptcy: Comparative and International Perspectives (Oxford, 2009).

Kisch, Guido, Der deutsche Arrestprozess (Wien, 1914), pp. 15; WaCH, Adolf, Der italienische Arrestprocess (Leipzig, 1868).

KNoF, Béla, Europäisches Insolvenzrecht und Schuldbefreiungs- Tourismus, en $Z \ln s O$ (2005).

KOHLER, Joseph, Lehrbuch des Konkursrechts (Stuttgart, 1891).

Kroppenberg, Inge, Die Insolvenz im klassischen römischen Recht (Köln, 2001).

Laroche, Peter - Pruskowski, Wolfgang - Schöttler, Alexandra - Siebert, Volker - VAllender, Heinz, Insolvenzrechtsreform 2. Stufe - die geplanten Änderungen in der Insolvenz natürlicher Personen, en ZIP. (2012).

Lemanissier, Jean, Faillité civile en Alsace et en Lorraine (Caen, 1939), pp. 12-34; 
Lencou, Dominique, La faillité personnelle et la banqueroute (Grenoble, Diss. Université de Bordeaux I, 1980).

LEPA, Brita, Insolvenzordnung und Verfassungsrecht (Berlin, 2002).

LeVeIlle, Jules-Louis, De l'abolition de la "contrainte par corps" (à propos de la loi projetée), en Revue Pratique de Droit Français, 22 (1866).

Levinthal, Louis Edward, The Early History of Bankruptcy Law (Pennsylvania, 1918).

LöвмANn, Benno, Der kanonische Infamiebegriff in seiner geschichtlichen Entwicklung unter besonderer Berücksichtigung der Infamielehre des Franz Suarez (Leipzig, 1956).

Longo, Giannetto, "Lex Iulia de cessione bonorum", en Novissimo Digesto Italiano, 9 (1963), pp. 810; Frederiksen, Martin W., Caesar, Cicero and the Problem of Debt, en Journal of Roman Studies, 56 (1966).

Luce, Victor, Abolition de la "contrainte par corps" (Brusells, 1867).

Mac Cormack, Geofrey, "Nexi", "iudicati" and "addicti” in Livy, en Zeischrift der Savigny-Stiftung, 84 (1967).

Mann, Bruce, Republic of Debtors: Bankruptcy in the Age of American Independence (Cambridge, 2002).

Manzini, Vicenzo, La bancarrota e la procedura fallimentare nel Diritto veneziano, con cenni sui grandi fallimenti del secolo XV, en Atti del Reale Istituto Veneto di Scienze, Lettere ed Arti, 85 (1926).

Marcucci, Monica, Insolvenza del debitore civile e "fresh start". Le ragioni di una regolamentazione, en Anal. giur. ec. (2004).

Martin, Nathalie, The Role of History and Culture in Developing Bankruptcy and Insolvency Systems: The Perils of Legal Transplantation, en Boston College Int. Comp. Law Rev., 28 (2005).

MeIER, Anke, Die Geschichte des deutschen Konkursrechts, insbesondere die Entstehung Reichskonkursordnung von 1877 (Frankfurt, 2003).

Mitteis, Ludwig, Über das Nexum, en Zeitschrift der Savigny-Stiftung, rom. Abt., 22 (1901).

Nicosia, Giovanni, La "manus iniectio": dal regime originario a quello della "manus iniectio pura", en Praesidia libertatis. Garantismo e sistemi processuali nell' esperienza di Roma repubblicana. Atti del VI Convegno di Copanello, 7-10 giugno 1992, en Silloge. Scritti 1956-1996 (Catania, 1998), II.

Obermüller, Manfred, Kreditsicherheiten in der Verbraucherinsolvenzreform en ZVI. (2012).

PACE, Giacomo, Contrainte par corps: l'arresto personale per debiti nell'Italia liberale (Torino, 2004).

PAPE, Gerhard - Grote, Hugo, Das neue Insolvenz-und Restschuldbefreiungsverfahren. Was die lange überfällige Reform bringt - und ob sie Sinn macht, en AnwBl (2012).

PAPE, Gerhard, Verbraucherinsolvenz 2012. Gefühlter und tatsächlicher Reformbedarf, en $Z V I$ (2012).

Peppe, Leo, Studi sull' esecuzione personale, I: Debiti e debitori nei primi due secoli délia repubblica romana (Milano, 1981).

Pertile, Antonio, Sotoria della procedura (continuazione), en Storia del Diritto italiano dalla caduta dell impero romano all codificazione (Bologna, 1966), VI,2.

Purpura, Gianfranco, La pubblica rappresentazione dell'insolvenza. Procedure esecutive personali e patrimoniali al tempo di Cicerone: Convegno "Lo spettacolo della giustizia a Roma: le orazioni di Cicerone" (Palermo, 2006). 
QueNillet, Martine, La bonne foi du débiteur surendetté: une voie sans issie, en $L P A$., 5 (1992).

Rodríguez Otero, Lino, El enigmático “nexum” como precedente de la hipoteca, en Revista Critica de Derecho Inmobiliario, 677 (2003).

Santarelli, Umberto, Per la storia del fallimento nelle legislazioni italiane dell'età intermedia (Padova, 1964).

SCHäFER, Thiemo, Der Eröffnunggrund der Überschuldung (Baden-Baden, Diss. Köln, 2012).

Schmerbach, Ulrich, Vereinfachung des Restschuldbefreiungsverfahrens, en ZinsO (2012).

Schönen, Simone, Verbraucherinsolvenzrecht im internationalen Vergleich unter besonderer Berücksichtigung der Vorschriften zur Restschuldbefreiung (Teil II), en ZVI. (2010).

Solazzi, Siro, Studi sul concorso dei creditori nel Diritto romano, en Atti della R. Accademia dei Lincei, 36 (1920).

SozA, María de los Ángeles, El "bonorum emptor": su posición jurídica. Sumario. Procedimiento concursal. La posición jurídica del "bonorum emptor" (Madrid, 2008).

Spann, Michael, Der Haftungszugriff auf den Schuldner zwischen Personal- und und Vermögensvollstreckung. Eine exemplarische Untersuchung der geschichtlichen Rechtsquellen ausgehend vom römischen Recht bis ins 21. Jahrhundert unter besonderer Berücksichtigung bayerischer Quellen (Münster, 2004).

SpOONER, Joseph, Fresh Start or Stalemate? European Consumer Insolvency Law Reform and the Politics of Household Debt en European Review of Private Law, 21 (2013).

Spooner, Joseph, Long Overdue, What the Belated Reform of Irish Personal Insolvency Law Tells Us About Comparative Consumer Bankruptcy, en American Bankruptcy Law Journal, 86 (2012).

Stephan, Guido, Stellungnabme zum Referentenentwurfeines Gesetzes zur Verkürzung des Restschuldbefreiungsverfahrens, zur Stärkung der Gläubigerrechte und zur Insolventfestigkeit von Lizenzen, en $Z V I$. (2012).

STRÄTZ, Wolfgang, Beiträge und Materialien zur Entwicklung von "Treu und Glauben" in deutschen Privatrechtsquellen vom 13. bis zur Mitte des 17. Jahrbunderts (Paderborn, 1974), I.

TABB, Charles, Lessons from the Globalization of Consumer Bankruptcy, en Law Soc. Inq., 30 (2005) 4.

ТАвв, Charles, The Historical Evolution of the Bankruptcy Discharge, enAmerican Bankruptcy Law Journal, 3 (1995).

TAeuber, Walther, Geld und Kredit im Mittelalter (Berlin, 1933).

The External Evaluation of Reg. No 1346/2000/EC on Insolvency Proceedings (Heidelberg - Luxemburgo - Viena, 2013) [disponible en: http://www.mpi.lu/uploads/media/ evaluation_insolvency_en.pdf].

ThOLE, Christoph, Vom Totengräber zum Heilbringer? Insolvenzkultur und Insolvenzrecht im Wandel. en JZ. (2011).

Tomás y VAliente, Francisco, La prisión por deudas en los Derechos castellano y aragonés, en Anuario de Historia del Derecho Español, 30 (1960).

Trancou, Georges, De l'extension de la faillite aux non-commerçants (Paris, Diss. Université de Paris, 1918).

Treiman, Israel, Acts of Bankruptcy: A Medieval Concept in Modern Bankruptcy Law, en Harvard Law Review, 52 (1938). 
TRIANDAFIL, Ernest, Histoire des voies d'exécution en droit romain. Époque des actions de la loi de la procédure formulaire (Paris, 1914).

Vigneau, Vincent - Bourin, Guillaume-Xavier - Cyril, Cardini, Droit du surendettement des particuliers (Paris, 2012).

Vollmershausen, Christiane, Vom Konkursprozess zum Marktbereinigungsverfahren (Münter, Diss. Ausburg, 2007).

Von HoInIngen, Hans, Beiträge zur geschichtlichen Entwicklung des strafbaren Bankerutts in Deutschland (Bonn, 1878).

WaCKe, Andreas, Athleten als Darlehensnemer nach römischen Recht, en Studia et Documenta Historiae Iuris, 44 (1978).

Wagner, Herbert, Die Entwicklung der Legalhypotheken am Schuldnervermögen im römischen Recht (bis zur Zeit Diokletians) (Köln, Wien, 1974).

Weiss, Egon, “Missio in possessionem”, en Paulys Realencyclöpadie der classischen Altertumswissenschaft, 15 (München, 1980) 2.

WELLER, Marc-Phillippe, Forum Shopping im Internationalen Insolvenzrecht? en IPRax (2004).

WENGER, Leopold, Institutionen des römischen Zivilprozessrechts (München, 1925).

Wessels, Bob, EU Insolvency Regulation: Where to go From Here? en International Insolvency Law Review, 3 (2011).

Whitman, James Q., The Moral Menace of Roman Law and the Making of Commerce: Some Dutch Evidence, en Yale Law Journal, 105 (1996).

WLASSAK, Moritz, "Cessio bonorum”, en Paulys Realencyclopädie der classischen Altertumswissenschaft (Stuttgart, 1899, 1970), III,2.

Woess, Friedrich von, Personalexekution und "cessio bonorum" im römischen Reichsrecht, en Zeitschrift der Savigny-Stiftung, rom. Abt., 43 (1922).

Yavetz, Zvi, "Existimatio", "fama" and the Ideas of March, en Harvard Studies in Classical Philology, 78 (1974).

Zambrana Moral, Patricia, Histoire de six articles du Code civil francais: les droits du debiteur, honneur et contrainte par corps en Revue Historique de Droit Français et Étranger, 82 (2004) 4.

ZIEGEL, Jacob, Facts on the Ground and Reconciliation of Divergent Consumer Insolvency Philosophies, en Theoretical Inquiries, 7 (2006). 